University of Rhode Island

DigitalCommons@URI

Open Access Dissertations

1975

\title{
Information Seeking Behavior
}

Dennis L. Sternlight

University of Rhode Island

Follow this and additional works at: https://digitalcommons.uri.edu/oa_diss

\section{Recommended Citation}

Sternlight, Dennis L., "Information Seeking Behavior" (1975). Open Access Dissertations. Paper 1115. https://digitalcommons.uri.edu/oa_diss/1115

This Dissertation is brought to you for free and open access by DigitalCommons@URI. It has been accepted for inclusion in Open Access Dissertations by an authorized administrator of DigitalCommons@URI. For more information, please contact digitalcommons-group@uri.edu. 


\section{INFORMATION SEEKING BEHAVIOR}

BY

DENNIS L. STERNLIGHT

DOCTORAL DISSERTATION

SUBMITTED IN PARTIAL FULFILLMENT FOR

THE DEGREE OF

DOCTOR OF PHILOSOPHY

IN

PSYCHOLOGY

UNIVERSITY OF RHODE ISLAND

1975 


\section{ABSTRACT}

Previous research has suggested that information seeking behavior is lawful and that the levels of information seeking are dependent upon alterations of the nature and conaitions under which the information is sought. However, in the previous research only two variables were manipulated. One was the similarity of the information to the subject seeking the information. This variable proved significant and could be used to. predict the relative levels of information seeking. The other variable was the race, black or white, of the individual for whom one was seeking information. This variable proved to be not significant.

The current study is designed to validate the findings of the first study and to expand the variables studied in order to more clearly specify the nature of information seeking behavior and its laws. In order to do this, the following research was carried out.

Forty, randomly selected, wheaton undergraduates were given attitude questionnaires to fill out. The first contained items which have been demonstrated to be of low importance and the second contained items demonstrated to be of high importance. From the responses of the subjects individual protocols were constructed to appear as similar or dissimilar to the subject. Thus, four protocols were available as follows: High Important Similar Information, Low Important Similar Information, High Important Dissimilar Information and Low 
Important Dissimilar Information. The items were presented one at a time to the subjects and they were allowed to seek as much or as little as they required in order to make a decision of acceptance or rejection. Twenty of the subjects were seeking in order to accept or reject a potential roommate. This was defined as a close social situation. Twenty of the subjects were seeking in order to accept or reject a potential member of the general community. This was defined as a distant social situation. Thus, the conditions under wich information seeking occured, varied on the dimensions of information similarity, information importance and social distance. The levels of information seeking were analyzed using a three way analysis of variance. All variables proved to have a statistically significant effect on information seeking behavior. The effects were interactive and are described in the body of the study. Under conditions of close social distance information seeking increased for items of information which were similiar and of high importance and decreased for items which were dissimilar and of low importance. Under conditions of far social distance information seeking increased for items of information which were dissimilar and of low importance and decreased for items which were similar and of high importance. 
ABSTRACT. ..........................

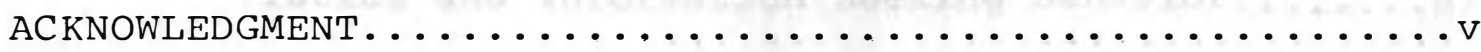

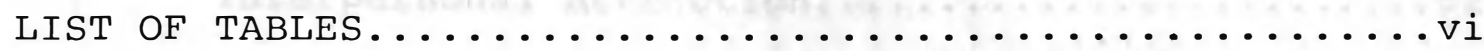

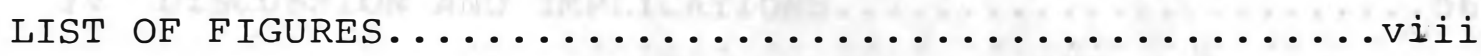

CHAPTER PAGE

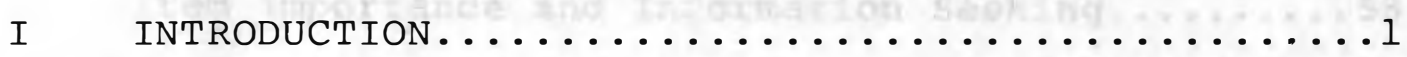

Interpersonal Attraction and Similarity.......

Prejudice and Similarity...............

Information Seeking Behavior - Similarity

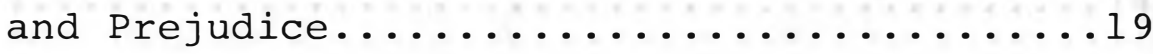

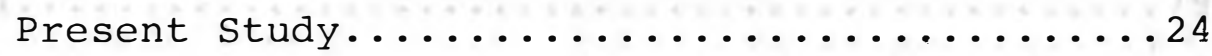

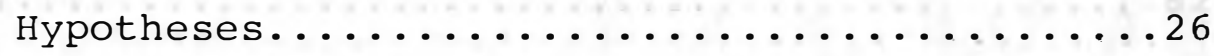

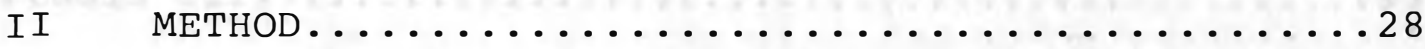

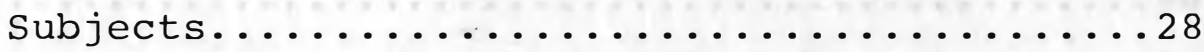

Materials and Procedure................28

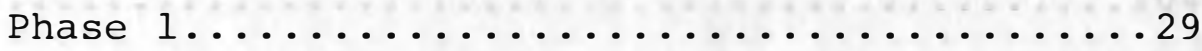

Interphase Interval.....................

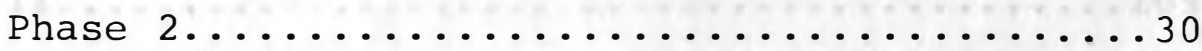

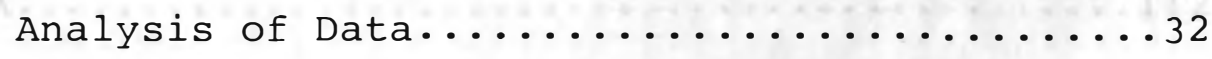

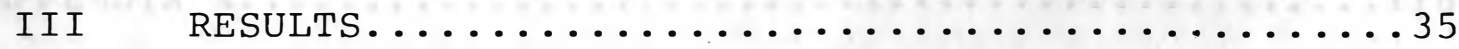

Effects of Similarity Item Importance and

Social Distance on Information Seeking

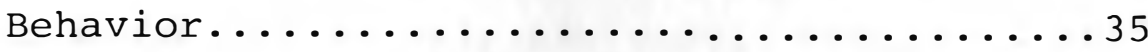


CHAPTER

II Correlations Between Personality Characteristics and Information Seeking Behavior......37

Interpersonal Attraction................. 52

IV DISCUSSION AND IMPIICATIONS............... 56

Similarity and Information Seeking...........56

Social Distance and Information Seeking.......57

Item Importance and Information seeking........58

Interpersonal Attraction................67

Personality and Information Seeking..........68

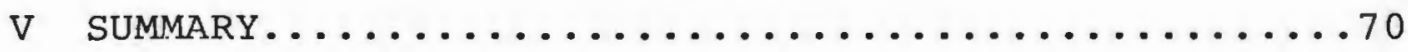

BIBLIOGRAPHY............................... 74

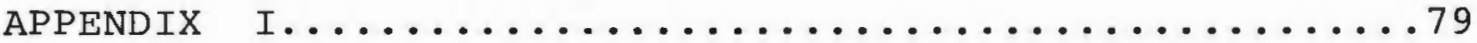

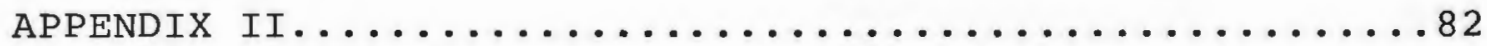

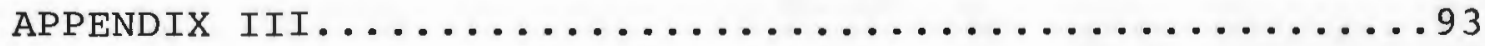

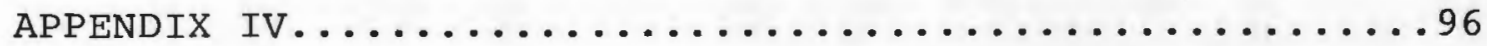

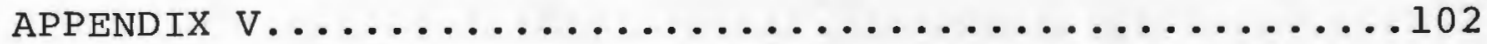

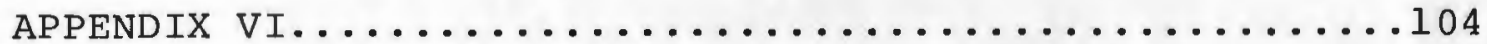

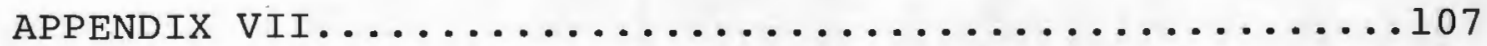

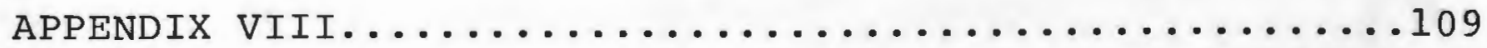

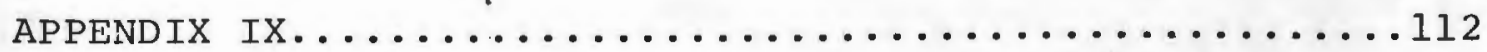

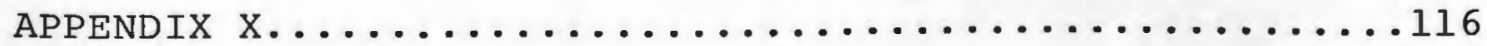

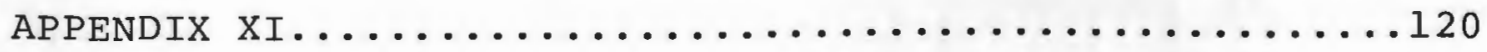




\title{
ACKNOWLEDGEMENT
}

This dissertation is dedicated to those without whom it could not have been written.

\author{
Albert J. Lott, Ph.D. \\ Peter F. Merenda, Ph.D. \\ Wayne F. Velicer, Ph.D.
}




\section{LIST OF TABLES}

TABLE

PAGE

I Total Number of Items of Information Used by Subjects in Selection of Potential Roommates

II Analysis of the Variance of Amount of Information Used to Accept or Reject Individuals under Different Information Conditions

III Main Effects of Social Distance at Both

Levels of Similarity

IV Main Effects of Similarity at Both Levels of Social Distance

$\mathrm{V}$ Main Effects of Item Importance at Both Levels of Social Distance

VI Main Effects of Social Distance at Both Levels of Item Importance

VII Main Effects of Item Importance at Both Levels of Similarity

VIII Main Effects of Item Similarity at Both Levels of Item Importance

IX Mean Number of Items Used by Subjects in Seeking Information under Different Information Conditions

$\mathrm{X}$ Correlations Between Levels of Information Seeking at Close Social Distance and Scores on Personality Tests 
XI Correlations Between Levels of Information Seeking at Far Social Distance and Scores on Personality Tests

XII Percentage of Acceptances and Rejections under Different Information Conditions

XIII Interactive Effect of Similarity, Item

Importance and Social Distance on Information Seeking 


\section{LIST OF FIGURES}

1 The Effect of Social Distance on Information Seeking Behavior at Two Conditions of Similarity

2 The Effect of Similarity on Information

Seeking at Two Conditions of Social

Distance

3 The Effect of Item Importance on Information Seeking at Two Conditions of Social Distance

4 The Effect of Social Distance on Information Seeking at Two Conditions of Item Importance The Effect of Item Importance on Information Seeking at Two Conditions of Similarity The Effect of Item Similarity on Information Seeking at Two Conditions of Item Importance 
INTRODUCTION

One of the aspects involved in the phenomenon of interpersonal attraction is the perception we come to have regarding the similarity or dissimilarity of another individual. As Griffitt (1974) points out, "It is apparent to the most casual observer that the tone of interpersonal interactions is to some extent linked to the expression of similar and dissimilar viewpoints by the participants." Thus, the process by which we come to formulate our attitudes toward another person is in one way or another associated with some exchange of information about the other person. The research to be presented here involves the information seeking process associated with interpersonal attraction and some of the stimuli which affect this information seeking bheavior.

The current research is an outgrowth of the vast amount of work which has been done with the similarity-dissimilarity variable accompanying interpersonal attraction and more particularly certain of the work which has been done in the area of prejudice. The current study is also a direct outgrowth of an unpublished master's thesis. (Sternlight 1974). Before presenting the present study the pertinent issues and data of these three areas will be considered.

\section{Interpersonal Attraction and Similarity}

The importance of similarity and its effect on inter- 
personal attraction has been recognized for a long time. In 400 B.C. Aristotle (translated 1932) commented as follows;

"And they are friends who have come to regard the same things as good and the same things as evil, they who are friends of the same people, and they who are enemies of the same people...

We like those who resemble us, and are engaged in the same pursuits... We like those who desire the same things as we, if the case is such that we and they can share things together." (pp. 103-105)

In the seventeenth century Spinoza (translated 1951)

more vigorously restated Aristotle's observation adding to it the notion of motivation.

\footnotetext{
"If we conceive that anyone loves, desires, or hates anything which we ourselves love, desire or hate, we shall thereupon regard the thing in question with more steadfast love, etc. On the contrary, if we think that anyone shrinks from something that we love, we shall undergo vacillation of soul.

... if follows that everyone endeavors, as far as possible, to cause others to love what he himself loves and to hate what he himself hates..." (p. 151)
}

Although these empirical observations have existed for a long time it was not until the 19 th century that more formalized work was begun in this area. In $1870 \mathrm{Sir}$ Francis Galton discussed 300 families which he studied and presented the notion that there appeared to be, "a tendency of like to like among intellectual men and women," and that, "the marriages of illustrious men with (equivalent) women...are very common. On the other hand, there is no evidence of a strongly marked antagonistic taste (republished 1952, p. 315)". 
Although the observations of Sir Francis Galton were still basically empirical, his publication was the first attempt to isolate and examine a population for the variables associated with attraction and marked the beginning of more formal studies which were to occur during the 20th century.

In the early 1900's a series of studies which was done investigating more closely the relationship between marriage and similarity of attitude, which had previously been observed. Basically these were correlation studies using the following format:

An attitude questionnaire was given to individuals which measured some attitude or areas of attitudes. For example, the following attitude item comes from the Vernon and Allport Test for Personal Values (1931): "The main object of scientific research should be the discovery of pure truth rather than its practical applications. (a) yes (b) no. "In addition, these studies frequently included measures which were designed to tap intelligence or cognitive functions. For example, Schooley (1932) included an orally repeated list of twenty words to determine short term memory ability. Correlations for these scores were then computed either for married couples alone or in comparison to individuals randomly selected. The basic notion was that the correlations between attitudes and/or intellectual skills would be high for married couples and in addition higher for married couples than for randomly selected individuals. 
These studies were later extended to friends using the same paradigm and with the same predictions.

Schuster and Elderton (1906) found that attitudes were positively correlated for the married couples they studied and reported correlations ranging from .11 associated with attitudes on reading to .73 for attitudes on religious feeling. The conclusion was that married couples do tend to resemble each other with regard to attitude.

Schiller (1932) gathered data not only for married couple pairs but also for associated random pairs. For the married couples Schiller reported positive correlations on all the characteristics he studied. The correlations for the random pairs were in general much lower and may were also megative. More specifically, the characteristics of body weight, arithmetic reasoning and general information were positively correlated for married couples and negatively correlated for associated random pairs. The data gave more support to the hypothesis that attraction and similarity are positively correlated.

These kinds of data indicating positive correlations between similar attitude, certain personal characteristics and married status continued to be reported by other workers. Kirkpatrick and Stone (1935), Morgan and Remmers

and Schooley (1936) all reported studies supporting the notion that there was an important relationship between similarity and interpersonal attraction. In addition, a question was raised by Kirkpatrick and stone (1935) regarding the cause-effect relationship of these data. 
They observed that these date could be understood either in terms of "assortative mating" or in terms of "attitudinal convergence."

That is, they raised the question as to whether people of similar attitude attract each other or whether people who attract each other subsequently become more similar in attitude.

The point of view that similarity leads to interpersonal attraction is most supported by Newcomb's (1956, 1961) research. He provided rent free housing at the University of Michigan for a group of male transfer students. Before these students arrived Newcomb collected data on their attitudes by mail. He then followed the students weekly giving them measures of attitude and interpersonal attraction. During the first the correlation between similarity and interpersonal attraction was . 13 but by the end of the 15 th week it had risen to .50 . Since the attitudes of students had not changed it seems that the similar attitude information, which was exchanged over the course of time, caused the shift in interpersonal attraction. More simply put, as a student learned of the similarity of another student his liking for that student increased.

on the other hand, Lott and Lott (1965) have presented a. review which gives support to the notion that liking and group cohesiveness can lead to increases in similarity of attitude. 
They predict..."that the more cohesive the group the greater the probability that members will develop uniform opinions and behaviors with respect to matters of consequence to the group." p. 301 .

To whatever extent either of these points of view operate it seems clear. that the exchange of information regarding attitudes is a critical component of interperson relations. In the first case the information exchange results in changes in liking and in the second case it facilitates intragroup identification and group expectancies.

Studies involving friends and small group interactions have also been conducted and yielded much the same results as the studies with married couples. Richardson (1940) ran correlations between similarity and interpersonal attraction using undergraduate friend pairs matched against undergraduate random pairs and adult friend pairs matched against adult random pairs. The correlations were negative. Correlations for the friend pairs ranged from .01 to .45 while those of the random pairs ranged from -.33 to .06 .

Using the small group model, Schachter (1951) conducted experiments in which groups were formed of 5-7 members who thought they were in a real club. To these groups Schachter added 3 stooges. After the groups were formed a discussion was started concerning the disposition of a fictitous individual whose case study had been presented. The stooges were instructed to talk last and presented views which 
were designed to appear as similar or dissimilar to the club members. After the discussion the group members were given the opportunity to rate the other members of the group by means of sociometric questions and ranking. As predicted, the stooges who had presented the dissimilar positions were rated the lowest for interpersonal attraction while those stooges who had presented a similar position were rated highest on the interpersonal attraction dimension. These studies again give support to the notion that similarity and interpersonal attraction are related in a powerful way.

Before further discussion of other research in this area it is important to consider three theoretical questions which have arisen in association with the paradigm used for these types of studies. Basically the paradigm is as follows:

(1) A subject is given a series of attitude questions.

(2) From the subject's answers bogus sets of answers are constructed to appear in one case dissimilar to the subject and in another case similar to the subject.

(3) The subject is then given the bogus sets of answers and asked to rate them on some dimension of interpersonal attraction.

(4) The predictions which have been supported so far involve the notion that, all things being equal, subjects will show a higher degree of interpersonal attraction to an individual who appears more similar to themselves than they will to an individual who appears dissimilar.

The first theoretical question arises from the fact that most of the studies have presented to the subject either answers which appear dissimilar or answers which appear similar. 
This would be justified only if there is a linear relationship across different degrees of similarity or dissimilarity. That is, what are the effects of half similar and half dissimilar or three quarters similar and one quarter dissimilar, etc. To answer these questions Byren (1962, 1965) conducted an experiment using the above paradigm but varying the proportion of similarity or dissimilarity of the bogus answers so that they appeared in all combinations of similarity and dissimilarity using the Interpersonal Judgment Scale (see Appendix I). That is, the items on the attitude questionnaire were designed to appear in the following combinations of similarity and dissimilarity: 10\% similar, 90\% dissimilar; $20 \%$ similar, $80 \%$ dissimilar; $30 \%$ similar, $70 \%$ dissimilar; $40 \%$ similar, $60 \%$ dissimilar;, etc. When Byrne plotted attraction as a function of proportion of similar attitudes he found that the relationship was linear. The straight line function was $Y=5.44 X-6.62$. Thus it would seem that the use of similarity-dissimilarity polarities in the bogus responses is justified and that what one is looking at in these types of studies is the greatest effect of the similarity-dissimilarity variables on interpersonal attraction.

The second theoretical issue involves the kinds of items which are used in the attitude questionnaires. Certain questions are of the class such that dissimilar answers are reflections of dissimilarity alone. For example, if one is asked what one's favorite color is, the reply may be "yellow." 
When this individual learns that another person answered "blue" to the question he or she will recognize that the response reflects difference but little more. On the other hand one may ask the question, "Do you believe in being honest?" Whether or not a person is honest, the answer will usually be "yes." Belief in honesty is a generally accepted ethical and moral position. It represents, unlike color preference, a consensus. When one learns that another person answered "no" to the question the perception is not only of difference or dissimilarity but also of deviance. Most studies using attitude questionnaires have used mixed items and, therefore, decreases in levels of interpersonal attraction may not only represent reaction to dissimilarity but also to deviance. To deal with this issue Byren (1971) has presented a 56 item attitude questionnaire whose answers are of sufficient heterogeneity to ensure that dissimilar responses will be perceived maximally as dissimilar and minimally as deviant. That is, he started with a great many items and kept only those for which all the possible responses were present and evenly distributed. It is this questionnaire which will be used in the present study. (see Appendix 2).

The third theoretical issue involves the question of topic importance. Byrne and Nelson (1964, 1965) fe].t that it was common sense that issues of high importance should have a greater affect on interpersonal attraction than issues of low importance. They conducted experiments in which similar and 
dissimilar responses were presented to subjects with respect to their occurrence on important or unimportant items. Subjects were given an attitude questionnaire which they not only answered but also rated according to the importance of each item. The 14 most important items were chosen. Then bogus protocols were designed so that there were responses which appeared similar or dissimilar on important items and similar or dissimilar on unimportant items. Thus, importance was varied between bogus protocols. The results showed the usual effect of similarity and dissimilarity on interpersonal attraction but no effect of item importance in interpersonal attraction. That is, similar bogus protocols consisting of low importance it.ems elicited the same positive interpersonal attraction ratings as the similar bogus protocols made up of items of high importance. The same was true for the dissimilar bogus protocols. Both the important and unimportant items elicited the same negative interpersonal attraction judgments. In later research however, Byrne, London and Griffitt (1968) designed the study so that importance could be manipulated within bogus protocols rather than between bogus protocols as had been done before. Subjects were able to rate protocols which had both important and unimportant items within them. Sometimes it was the important items which appeared as similar and the unimportant items which appeared as dissimilar and sometimes the reverse was true. In this study there was an effect seen from the importance of the item. When a subject rated a bogus 
protocol in which a greater proportion of similarity appeared on the important items he gave a higher interpersonal attraction rating that he did if the similarity appeared in greater quantity on unimportant items. That is, if important and unimportant items appeared on the same protocol, an interpersonal attraction discrimination could be made by subjects. This point has direct bearing on the current study and will be discussed further when the details of the present study are presented.

Prejudice and Similarity

In the same way that two views have been presented regarding the sequence of interpersonal attraction and similarity--namely that similarity leads to liking or, that liking leads to similarity--two views have been presented regarding prejudice. The first view, for which Triandis is the most powerful spokesman, puts forth the notion that differences in color are enough to act as stimuli for prejudice. As Triandis (1961) puts it, "People do not exclude other people from their neighborhood, for instance, because other people have different belief systems; they exclude them because they are Negroes." The opposite point of view can be seen in a statement by Rokeach (1960): "The major finding in all samples was that discriminatory preferences are made primarily on the basis of belief congruence rather than on the basis of ethnic or racial congruence." This latter view has come to be known as the belief view of prejudice. 
Triandis has done a great deal of research in an attempt to support the opinion that actual racial differences are the most important factor in determining prejudice. In 1960, he utilized a social distance scale consisting of 15 statements selected from an original list of 59. The selection was based upon items which yielded a successive interval scale according to the method of Edwards (1957, Chapter 5). Subjects were then given descriptions of different stimulus individuals and asked to rate these individuals on the 15-item social distance scale. Stimulus individuals consisted of descriptions such as, "Negro," "different religion," "Portuguese," "physician," and "Greek," "truck driver," "white," "same religion." Triandis (1960) found that, "For the subjects of this study race is by far the most important factor determining social distance."

Triandis (1961) then added to the characteristics of the stimulus individuals a description of 13 ways to live prepared by Morris (1956). These consist of brief descriptions of different philosophies of life. For example, way number one:

In this 'design for living' the individual actively participates in the social life of his community, not to change it primarily, but to understand, appreciate, and preserve the best that man has attained. Excessive desires should be avoided and moderation sought. One wants the good things of life but in an orderly way. Life is to have clarity, balance, refinement, control.

Vulgarity, great enthusiasm, irrational behavior, impatience, indulgence are to be avoided. Friendship is to be esteemed but not easy intimacy with many people. Life is to have discipline, intelligibility, good manners, predictability. Social changes are to 
be made slowly and carefully, so that what has been achieved in human culture is not lost. The individual should be active physically and socially, but not in a hectic or radical way. Restraint and intelligence should give order to an active life.

Subjects were asked to read these 13 different philosophies and to indicate their most and least preferred way of life. They were then instructed to think of their most preferred way of life when the stimulus individual included "same philosophy as you" and to think of their least preferred way of life when the stimulus individual included "different philosophy than you." The conclusions were not different from the 1960 study and Triandis maintained that race was the most important factor associated with social distance.

Triandis (1964) conducted further studies in which he found five factors associated with social acceptance. These factors were:

(1) Formal Social Acceptance, which included such items as, "I would admire the ideas of," "I would ask for opinion of," etc.

(2) Marital Acceptance, which included such items as, "Fall in love with," "Go out on a date with," etc.

(3) Friendship Acceptance, which included such items as, "Accept as an intimate friend," "Go fishing with," etc.

(4) Hostile Acceptance, which included such items as, "Permit to do me a favor," "Admit as a tourist in my country," etc.

(5) Interaction with Superiors-Subordinates, which includes such items as, "Recommended by." 
In examining these factors Trianais and Davis (1965) found that only some of the factors supported the earlier contention that race is the most important variable for social distance and prejudice. They found that Factor 1 is responded to on the basis of perceived belief and also, depending upon the level of prejudice of the subject, it was found that Factors 3 and 5 acted similarly. Only Factors 2 and 4 were responded to on the basis of race per se and these items, by and large, represent intimate interpersonal behavior of small social distance, exclusively.

It is obvious that in his later work Triandis changed from his 1960 portion which considered race as the primary variable affecting social distance and prejudice included the belief theory view as part of his own theory.

Many researchers have investigated the belief theory. Basically there have been two experimental paradigms. The first consists of having subjects respond to paper and pencil measures of attitudes. From these questionnaires other "stimulus protocols" may be established giving the appearance of being similar or dissimilar. These are then associated with stimulus individuals who vary according to race, religion, ethnic group, etc. The original subjects are then asked to respond on some social dimension to different stimulus individuals (Byrne, 1961; Byrne \& McGraw, 1964; Stein, Hardyck, Smith, 1965; Robinson \& Insko, 1969). Unlike the original stimulus individuals of Triandis (1960), for whom differences 
were transmitted by the statement of difference, these stimulus individuals have had their characteristics created out of the pre-measured characteristics of the subjects themselves. That is to say, Triandis would ask a subject to respond to a bogus subject described as black, truck driver, doesn't believe in God. If the subject responded with, "strongly believe in God," the bogus individual could be presented as being different by presenting his response as, "strongly do not believe in God."

Because of concerns that paper and pencil measures alone are limited in their ability to be generalized to real life situations, a second paradigm has been used.

In this paradigm subjects have real life encounters with individuals holding similar or dissimilar beliefs. These stimulus individuals also vary in race and attitude and subjects are asked to respond to them in some sort of public interpersonal behavioral situation (Rokeach \& Mezei, 1966). The notion that prejudice results primarily from perceived difference of belief has been extensively explored by Rokeach, Smith, and Evans (1960). These researchers used the first paradigm to study the belief variable associated with racial as well as religious differences. As they put it, "... we hypothesize that insofar as psychological processes are involved, belief is more important than ethnic or racial memberships as a determinant of social discrimination." Rokeach \& Mezei (1966) studied the same issues using the second paradigm. 
In the 1966 study their method was as follows:

A naive subject engages four strangers, confederates of the experimerter, in a group discussion about an important or situationally relevant topic. Two of the confederates are white and two are Negro. One white and one Negro agree with the subject, and one white and one Negro disagree with him. The subject is then asked to state preference for two of the four confederates.

One of the situations involved a university setting and the other involved a situation in which subjects were actual job applicants.

Using the two paradigms, both the 1960 study (Rokeach, Smith, \& Evans) and the 1966 study (Rokeach \& Mezei) yielded results consistent with the belief theory and showed that similarity or dissimilarity of perceived belief was the major factor in social choices. The authors were careful to point out in both studies that the belief hypothesis was only being tested in the absence of external pressure to discriminate along racial lines.

Byrne (1961) extended the belief theory to studies of strangers. He hypothesized that "a stranger who is known to have attitudes similar to those of the subject is better liked (attraction hypothesis) than a stranger with attitudes dissimilar to those of the subject." In addition he proposed that strangers with similar attitudes are judged to be more intelligent, better informed, more moral, and better adjusted (evaluation hypothesis) than a stranger with dissimilar attitudes. The study included both black and white strangers. The pre-testing of subject attitudes and the subsequent use of 
bogus stimulus individuals was again used. The subjects were made to respond to the manufactured attitude questionnaires on the basis of an interpersonal attraction scale (i.e., "Would you like to work with this person?") and four evaluation scales, intelligence, knowledge, morality, and adjustment. Both the attraction and evaluation hypothesis were confirmed and in this study attraction and evaluation were affected primarily by perceived belief of the stimulus individuals and not their racial characteristics.

Byrne and wong (1962) then reversed the question. They hypothesized that highly prejudiced individuals would perceive greater dissimilarity of belief in the direction of their prejudice. That is, a prejudiced white subject, given a white and black stimulus individual would perceive the black stimulus individual as having a more dissimilar belief system than the white stimulus individual.

Weeks after establishing the degree of prejudice of the subjects they were asked to rate individuals on the basis of physical appearance. Byrne and wong reported that, "statistically significant trends toward perceived dissimilarity were found in the hypothesized direction."

Byrne and McGraw (1964) did the same kind of study with the addition of a photograph to the bogus protocol. With this methodological difference the high-prejudice subjects were found to rate Negroes more consistently negative, in terms of race, no matter what their belief. Thus, there was a primary effect of race similar to that described by the 
Triandis studies.

In later studies (Inski \& Robinson, 1967; Robinson \& Inski, 1969) subjects' perception of individual was again found to be dependent upon both race and perceived belief depending upon the intimacy of the social situation involved. That is, situations like marriage were more affected by race than belief. Like Triandis (1964), Robinson and Insko (1969) found that the relative effects of race or belief depended upon the kind and quality of information.

Stein, Hardyck, and Smith (1965) conducted a series of studies in which they used a modified form of the attitude questionniare. They were interested in a teen-age population and constructed a specialized teen-age attitude questionnaire which had items appropriate for that age group. The items concerned attitudes of other people which were to be judged as desirable or not; for example, "Try to please their parents by the things they do," "Let everybody have his fair say in running things in the school," and "Go along with what most other students do and stand for, not be too different." They also found both race and belief effects and concluded from their data that when little information was provided, subjects responded on the basis of race but when relevant information was provided decisions concerning interpersonal attraction, social distance and evaluation were made on the basis of belief. This notion, that as information input increases, primary racial effects disappear and one sees the principal effect of 
prejudice within the sphere of the belief system, was further supported in a study by Mezei (1971). Mezei examined subjects' reactions to white-similar (similar in attitude questionnaire responses), white-dissimilar stimulus individuals. He reported, that using a multiple regression technique (Hays, 1963, p. 504), he was able to partial out the effects of social pressure on the race and belief prejudice scores. He concluded that, "The results show that when the effect of perceived social pressure on both race and belief prejudice is statistically eliminated, belief prejudice is stronger than race prejudice, even for intimate social interactions." Thus, it appears that the amount of information about another's belief system is a major variable in determining prejudice. The more information we have about an individual the less likely we are to respond on the basis of race prejudice.

\section{Information Seeking Behavior - Similarity and Prejudice}

The studies which have been previously described have focused on the effect of similar or dissimilar information on interpersonal attraction. The information which has been used to represent an individual for whom a subject was to make attraction judgments has traditionally been presented all at the same time. In the Stein, Hardyck and Smith (1965) study, for example, information about another person was utilized only insofar as it was or was not present. That is, when information was available it was presented to a captive subject 
who could not freely choose to reject or ignore it. In the real world the conditions are quite different. People may or may not seek out information about another person and the stimuli which "shut down" or "turn on" information seeking behavior are critical to the subsequent modes of evaluation. Sternlight (1974) conducted a study in which the focus was on the information seeking behavior of subjects. In this study the usual paradigm was followed. Subjects were give an attitude measure and then bogus protocols were constructed using the items from the original attitude questionnaire. Subjects were told that four prospective roommates has filled out a questionnaire like the one they had filled out and that they were to select of reject these people as roommates based on their questionnaire responses which would be shown. As usual, the bogus questionnaires were constructed to appear similar or dissimilar to the subjects who were going to look at them. In addition, pictures of the "potential roommates" were provided. These pictures were either of black or white students, so that four selection conditions existed; black-similar, blackdissimilar, white-similar, white-dissimilar. However, the questionnaires were not presented in total but rather each of the items was in a separate envelope, which the subject went through one at a time, going only so far as they needed to in order to make a comfortable judgment as to whether or not they wanted the prospective roommate. Thus it was the effect of similarity and or race on information seeking behavior which was being studied. 
There was not appreciable effect of racial differences on information seeking behavior but there was a marked effect of similarity and dissimilarity on information:sseeking behavior. subjects sought on the average $38 \%$ more information about another person simply on the basis that the information appeared to the subject as similar to his own attitudes. What the study seemed to show is that given the same "need to know" (the task of roommate selection) people sought more information about others when they believed the others to be similar to themselves and less information when they believed the others to be dissimilar to themselves (see Table I). This data suggest a simple, empirical answer to the question, what is it about similarity that contributes to interpersonal attraction friendship and marriage. It would seem that there is a compelling reaction to the perception of similarity in others, which causes increased desire for more information about that person, which in turn results in maintenance of contact. The maintenance of contact allows for the development of such things as interdependence, intimacy and positively reinforcing contingencies. There is some concern, however, that the items in the study measured not only attitude but also deviance from consensus and the conclusions one can draw from the information seeking study are limited by this. For example, one of the items asked whether or not one believed that a roommate should be honest. The subjects overwhelmingly responded yes to this question so that when the bogus response, 
TABLE I

TOTAL NUMBER OF ITEMS OF INFORMATION USED

BY SUBJECTS IN SELECTION OF POTENTIAL ROOMMATES*

Number of Items. Mean $\begin{array}{r}\text { Standard } \\ \text { Deviation }\end{array}$

Similar

Potential

Roommate

Dissimilar

Potential

Roommate

White

Potential

Roommate

Black

Potential

Roommate $\begin{array}{lll}1172 & 14.7 & 5.9\end{array}$

$\begin{array}{lll}767 & 9.6 & 4.3\end{array}$

$\begin{array}{lll}952 & 11.9 & 5.7\end{array}$

987

12.3

$5 \cdot 8$

*Sternlight (1974) 
"Do not believe in a roommate being honest," was presented if not only represented dissimilarity but also deviance from what seemed to be a norm of the experimental sample. Another issue raised by this study involves whether or not htere is an increased amount of information seeking for similarity on items of low importance as well as items of high importance. If there is, as was just proposed, an intrinsic property of similarity which causes increased information seeking, then one would expect to see this as generally true across the class of item importance. If this were found, then it would be easier to believe that an increase in information seeking behavior, associated with the perception of similarity of attitude in another person, is a general phenomenon. If it were additionally found that the information seeking level were proportional to the importance of the items, one could reasonably conclude that information seeking behavior is predictable. This general issue has been raised before by Bryne and Nelson $(1964,1965)$ and has been previously discussed. However, they raised the issue in terms of whether or not there was a differential effect for item importance or interpersonal attraction. Even though this is true a consideration of their findings has relevance for the information seeking behavior issue. They were surprised to find no effects. That is, no difference was found in level of interpersonal attraction between a bogus protocol of high importance versus one of low importance. It is proposed here that if there is a differential effect it occurs at the level of information seeking behavior. 
Further, the reason they did not find an effect is because there was no discrimination to seek. Subjects rated a protocol on the basis of similarity or dissimilarity alone (subjects, for example, who had a high importance item protocol never saw a low importance protocol). This notion is supported by their later finding. Recall that, when a subject was presented with a mixed high importance-low importance protocol there was a discrimination to be sought and found--subjects began to perceive, during the seeking process, that items were high or low importance and were being varied at each of these levels for similarity or dissimilarity. The effect on interpersonal attraction could be observed when the subjects had an item importance difference to actually find within the protocol. In the first case any one subject had only a one level item importance protocol to use. For that subject there was nothing to seek or find.

\section{Present Study}

The present study is designed to explore further the variables involved in the control of information seeking behavior. The similarity variable, which was significant in the previous study, (Sternlight 1974) will be continued in the current design in order to further validate its role in controlling information seeking behavior. There are two other reasons for further exploration of the similarity variable. In the previous study the questionnaire which was used was not 
free of items which transmitted a sense of deviance when only dissimilarity was intended. In response to this concern the items which will be used in the current study have been selected because they have been demonstrated to be free of the suggestion of deviance in cases where the answers to the questions are dissimilar to the subject:s responses (Byrne 1971). In addition, the previous study did not offer the opportunity to test the interactive effects of similarity with other variables asscciated with the information seeking process. The present study will include some of these additional variables.

Another variable which has proved to be of considerable importance in the literature from which the present study was suggested is that of interpersonal or social distance. Triandis (1964) was able to demonstrate a social distance factor in his work on interpersonal attraction. Byrne (1971) has also raised the question as to whether or not a person's response to similarity and dissimilarity in another individual is a function of how much social or interpersonal distance exists in the relationship.

In terms of the present study the question will be raised in terms of the effect of social distance on information seeking behavior. That is, do we seek information differently for close social situations as compared to distant ones? Thus, subjects will be asked to seek information under two different sets of instructions. The first will be to seek information in order to select a roommate and the second will 
be to ask subjects to seek information in order to make a decision as to whether or not they felt they would like to have the particular individual, for whom they were seeking information, as a student at the University of Rhode Island.

Another issue which has been discussed is the influence of item importance on information seeking behavior. The question has been raised as to whether or not the importance of the items which one views affects the information seeking style of the seeker. In the present study this variable will also be manipulated in order to observe the effect of low importance items as compared to high importance items, on information seeking behavior.

Hypotheses:

(1) The similarity or dissimilarity of a stimulus individual will affect the amount of information a subject requires to make an interpersonal evaluation.

(2) The importance of the information about a stimulus individual will affect the amount of information a subject requires to make an interpersonal evaluation.

(3) The social distance of the task will affect the amount of information required by a subject in order to make an interpersonal evaluation of a stimulus individual.

(4) There is an interaction between similarity and 
social distance which will affect the amount of information a subject wili require to make an interpersonal evaluation of a stimulus individual.

(6) There is an interaction between the importance of the information and the social distance which will affect the amount of information a subject requires to make an interpersonal evaluation of a stimulus individual.

(7) There is an interaction between the similarity of a stimulus, the importance of the information and the social distance which will affect the amount of information a subject requires to make an interpersonal evaluation of a stimulus individual.

At this time it is felt that increased similarity results in increased information seeking, decreased item importance results in increased seeking and decreased social distance results in increased information seeking. 
METHOD

\section{Subjects}

The subjects consisted of 40 undergraduate female students from wheaton college who. were randomly selected from the class roster.

\section{Materials and Procedure}

The Byrne, Nelson, Griffitt Questionnaire (NBGQ) which was used was developed by Nelson (1965), Griffitt and Byrne (1970) and (Byrne, 1971). The BNGQ consists of 56 items which cover a wide variety of topics and responses to the questions are given by subjects on a 6 point Likert-type scale (see Appendix II). These responses give subjects the opportunity to express attitudes toward the items which range from strong agreement to strong disagreement. Each item was, in addition, weighted by 138 undergraduates at the University of Texas (Byrne, 1971, p. 63) for its level of importance. Thus the scale can be arranged in a hierarchy from the item of most importance to the item of least importance. Nelson (1965) and Griffitt and Byrne (1970) report test-retest Pearson productmoment correlations ranging from .55 to .95 with a two week intertest interval. The present study will utilize the items rated the 20 most important and the 20 least important. In addition to the fact that the items in this questionnaire are 
weighted for topic importance they were also selected on the basis of their ability to elicit heterogeneous responses. Therefore, there is no consensus associated with answers to these questions and subjects viewing dissimilar responses will tend not to see them as deviant responses.

\section{Phase 1}

Subjects were asked to complete the 40 item version of BNGQ. The instructions were as follows:

"The questionnaire you have been given offers you the opportunity to express your attitudes on a variety of issues. The answers which you are to select range from strong degrees of acceptance and approval of an idea to strong degrees of rejection or disapproval of an idea. You are to select the answer which you feel most closely approximates your actual attitude toward the issue presented and indicate this answer with a check mark. Are there any questions?

\section{Interphase Interval}

The interphase interval lasted two weeks. During this time four "stimulus protocols" for each subject were constructed. On the basis of the subject's protocol which she filled out during phase one, stimulus protocols were designed to appear to the subject as similar to the subjects own responses or dissimilar to the subject's own responses. In order to keep the "stimulus protocols" for appearing too obvious they were constructed much the same as those of the first Information seeking Study (Sternlight, 1974). That is, the similar "stimulus protocol" consisted of $75 \%$ similar responses .with the dissimilar responses appearing in positions 4, 8, 10 , 
14, and 20. The dissimilar "stimulus protocol" consisted of 75\% dissimilar responses with the similar responses appearing in positions $4,8,10,14$, and 20 . Thus the similar protocols did not appear entirely dissimilar. In addition the items were separated into protocols with only high importance items and protocols with only. low importance items. The four "stimulus protocols" foe each subject were thus:

(1) Similar responses to high importance items.

(2) Similar responses to low importance items.

(3) Dissimilar responses to high importance items.

(4) Dissimilar responses to low importance items. The importance of the items presented was validated by Byrne and Nelson (1964) by presenting 56 items to 138 undergraduates at the University of Texas (see Appendix 3 ). These subjects were asked to rate each item on importance using a 4-point scale of importance. Twenty of the items being used in the BNGQ are the items which were rated as the highest importance items and twenty of the items were the items rated as the least important.

\section{Phase $\underline{2}$}

Subjects were presented with four packages each containing 20 envelopes. Each package represented one "stimulus protocol" varied on the dimensions of similarity and item importance. Each envelope within a package contained one item from the BNGQ and a response to that item. Package one contained 20 similar responses to high importance items, package 
two contained 20 dissimilar responses to high importance items, package three contained 20 similar responses to low importance items and package four contained 20 dissimilar responses to low importance items. The order of presentation varied randomly for each subject.

Instructions for the task involving far social distance were as follows:

\begin{abstract}
"We are interested in the process by which individuals are able to form impressions of other individuals on the basis of limited information concerning their attitudes. Each of the packages you have received contains 20 envelopes with an individual's responses to the questions on the questionnaire which you took two weeks ago. Each envelope contains one item and its response. They are numbered from 1 through 20 and you are to open each envelope in order. We are not only interested in your impression but also the amount of information it takes for you to form that impression. Sometimes people need a lot of information to make a judgment and sometimes it requires little information. You are to use only as much information (as many envelopes) as you need to make a comfortable decision about whether or not you fee]. that you would like to have the individual attend wheaton college. When you have made your decision indicate it in the space provided as well as the number of envelopes you used to come to that decision."
\end{abstract}

Instructions for the (close) social distance task were as follows :
"We are interested in the process by which individuals make decisions about other individuals on the basis of limited information concerning their attitudes. Each of the packages you have received contains 20 envelopes with an individual's responses to the questions on the questionnaire which you took two weeks ago. Each enve- lope contains one items and its response. They are numbered from 1 through 20 and you are to open each envelope in order. We are not only interested in your impression but also the amount of information it takes for you to form that impression. Sometimes people need a lot of information to make a judgment and sometimes it requires little information. You are to use only 
as much information (as many envelopes) as you need to make a comfortable decision as to whether or not you would like the person for a roommate. When you have made your decision indicate it in the space provided as well as the number of envelopes you used to come to that decision."

\section{Analysis of Data}

The results were anlayzed using a three way analysis of variance. The design can be represented as: Social Distance Similarity of Attitude Item Importance
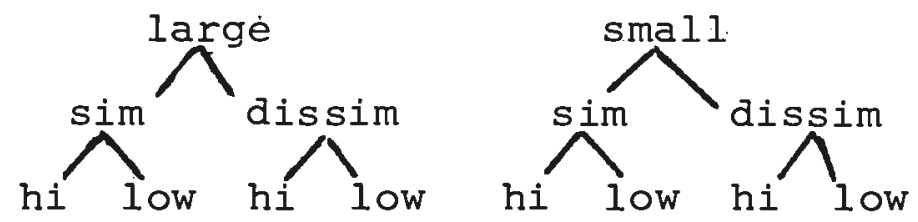

Independent samples for social distance and repeated measures for similarity and item importance were used.

In addition, some exploration of the relationship between the level of information seeking and personality characteristics was conducted. The design of the study permitted the identification of high information seekers versus low information seekers and the question is whether or not the levels of information seeking under all conditions is related to some personality characteristic of the individual seeker.

In order to do this three personality tests were administered to the sample population and the correlations were calculated between scores of the personality tests and the levels of information seeking overall as well as under each conditon.

The first personality test was the Rigidity Scale 
(Rehfisch, 1958). This was chosen because it seems that the rigid personality would be definition have their minds made up at earlier levels as compared with the flexible personality. The Rigidity Scale was designed to measure personality rigidity which is characterized by constriction and inhibition, conservatism, intolerance of disorder and ambiguity, observational and perserverative tendencies, social introversion and anxiety and guilt. It consists of 39 true-false items and has been demonstrated to have a split-half reliability of .72 . Validity was demonstrated by correlating raters judgments with test scores and was found to be .73 .

The second personality test was the Self-Acceptance Scale (Berger 1952). This was chosen because it was felt that individuals who are accepting of self use information to the greatest degree for its intrinsic value. That is, they would use information about others attitudes less to define self and as a result be able to make decisions without excessive seeking. The Self Acceptance Scale contains 36 items which are answered on a Likert type scale of most like me to least like me. Speraman-Brown estimates of reliability equalled or exceeded .75 for several samples using the Berger Scale. Validity was tested by comparing the Berger Scale with other scales of self-acceptance. Correlations between .49 and .84 were found.

The third personality test was the James' InternalExternal Locus of Control Scale (Rotter 1966). This was chosen 
because it was felt that the way an individual responds to information input has a great deal to do with where the locus of control is. The scale contains 60 Likert items which are responded to on a strongly agree-strongly disagree continuum. Test-retest reliability over a three month period was .86 .

The inclusion of these personality measures in the framework of the information seeking study is purely exploratory and its value lies in future studies of this nature. 
RESULTS

Effects of Similarity Item Importance and Social Distance on Information Seeking Behavior

A three way analysis of the variance, with independent samples at levels of social distance and repeated measures across levels of similarity and item importance, was performed for the amount of information used to accept or reject individuals under different information conditions (see Table II). The interaction effects of social distance and item similarity, social distance and item importance, item similarity and item importance are all statistically significant $(p<.01)$. The main effects were not statistically significant $(p>.05)$. In order to interpret the significant interaction effect, main effect tests were performed for each of the three significant interactions.

The effect of social distance on information seeking was statistically significant $(p<.01)$ at both levels of : social distance (see Table IV and Fig. 2).

The effect of item importance on information seeking was statistically significant $(p<.01)$ at both levels of social distance (see Table V and Fig. 3).

The effect of social distance on information seeking was statistically significant $(p<.01)$ at both levels of item importance (see Table VI and Fig. 4). 
The effect of item importance on information seeking was not statistically significant $(p) .05)$ when the information one was seeking was similar co the subject but was statistically significant $(p<.01)$ when the information one was seeking was dissimilar (see Table VII and Fig. 5).

The effect of item similarity on information seeking was not statistically significant ( $p) .05)$ when the information one was seeking was of high importance but was statistically significant $(p<.01)$ when the information one was seeking was of low importance (see Table VIII and Fig. 6). The mean number of items used by subjects in seeking information under different conditions is presented in Table IX. A test of $\mathrm{F}_{\max }$ was not significant $\underset{\max }{\left(F_{\max }\right.}=5.1 ; \mathrm{df}=8$, 19; p>.01).

It should be noted that there were two kinds of interactions observed. Social distance, as it was manipulated at its two levels, seems to cause a reversal in the amount of information subjects used to select or reject individuals. A good example of this can be seen in Fig. 2. At close social distance on the average of 11.9 similar items were required to make decisions while only on the average of 6.6 dissimilar items were required. However, at far social distances on the average of 7.0 similar items were required while 13.2 dissimilar items were required. The same thing was seen for the interaction between social distance and item importance (see Fig. 3). At close social distance on the average of 10.7 high 
importance items were required to make decisions while only on the average of 7.8 low importance items were required. At far social distance on the average of 8.1 high importance items were required while 12, 2 low importance items were required. This reversal is what accounts for the lack of statistical significance of the main effects in the analysis of variance.

The second type of interaction occurred between the variables item importance and similarity. In this type there was statistical significance at only one level of each variable. That is when the information was similar, differences in item importance made no difference in the amounts of information required to make decisions (see Fig. 5). When the information was of high importance differences in the similarity made no difference in the amounts of information required. It was only at levels of dissimilar information of low item importance that differences in information seeking were observed.

Correlations Between Personality Characteristics and Information Seeking Behavior

The correlations between the scores for the three personality tests and the scores for information seeking at all levels are presented in Table $\mathrm{X}$ for seeking at close social distance and Table XI for seeking at far social distance. The variable number code is as follows: 
TABLE II

ANALYSIS OF THE VARIANCE OF AMOUNT OF
INFORMATION USED TO ACCEPT OR REJECT

INDIVIDUALS UNDER DIFFERENT INFORMATION CONDITIONS

\begin{tabular}{|c|c|c|c|c|}
\hline Source & SS & $d f$ & MS & $\mathrm{F}$ \\
\hline \multicolumn{5}{|l|}{ Between subjects } \\
\hline $\begin{array}{l}\text { Social Distance (C) } \\
\text { Error } \\
\quad \text { (Subjects w. groups) }\end{array}$ & $\begin{array}{r}32.39 \\
913.69\end{array}$ & $\begin{array}{r}1 \\
38\end{array}$ & $\begin{array}{l}32.39 \\
24.04\end{array}$ & 1.35 \\
\hline \multicolumn{5}{|l|}{ Within subjects } \\
\hline $\begin{array}{l}\text { Similarity (D) } \\
\text { Social Distance } \mathrm{x} \\
\text { Similarity }\end{array}$ & $\begin{array}{r}9.03 \\
1311.03\end{array}$ & $\begin{array}{l}1 \\
1\end{array}$ & $\begin{array}{r}9.03 \\
1311.03\end{array}$ & $\begin{array}{c}0.69 \\
100.86\end{array}$ ** \\
\hline $\begin{array}{l}\text { Error } \\
\quad(D \times \text { Subjects })\end{array}$ & 493.92 & 38 & 12.99 & \\
\hline $\begin{array}{l}\text { Item Importance (I) } \\
\text { Social Distance } \mathrm{x}\end{array}$ & $\begin{array}{r}14.40 \\
489.99\end{array}$ & $\begin{array}{l}1 \\
1\end{array}$ & $\begin{array}{r}14.40 \\
489.99\end{array}$ & $\begin{array}{l}3.39 \\
115.23\end{array}$ \\
\hline $\begin{array}{l}\text { Item Importance } \\
\text { Error } \\
\text { (I x Subjects) }\end{array}$ & 161.59 & 38 & 4.25 & \\
\hline $\begin{array}{l}\text { Similarity } \mathrm{x} \\
\text { Item Importance } \\
\text { Social Distance } \mathrm{x}\end{array}$ & 34.22 & 1 & 34.22 & $9.89^{\star \star}$ \\
\hline $\begin{array}{l}\text { Similarity } x \\
\text { Item Importance }\end{array}$ & 7.23 & 1 & 7.23 & 2.09 \\
\hline $\begin{array}{l}\text { Error } \\
\quad(I \times D \times \text { Subjects })\end{array}$ & 131.56 & 38 & 3.46 & \\
\hline Total & 3599.05 & 159 & & \\
\hline
\end{tabular}

$\star * \quad p<.01$ 
TABLE III

MAIN EFFECTS OF SOCIAL

DISTANCE AT BOTH LEVELS OF SIMILARITY

\begin{tabular}{lllll} 
Source & SS & df & MS & F \\
\hline
\end{tabular}

Social Distance at the Level of Similarity

464.80

$1 \quad 464.80$

$25.09^{* *}$

Social Distance at the Level of Dissimilarity

876.80

$1 \quad 876.80$

$47.34^{* *}$

Error

(pooled: Sub. w. 1407.62

gps. \& D x subjects)

76

18.52

Total

2749.22

78

** $\mathrm{p}<.01$ 


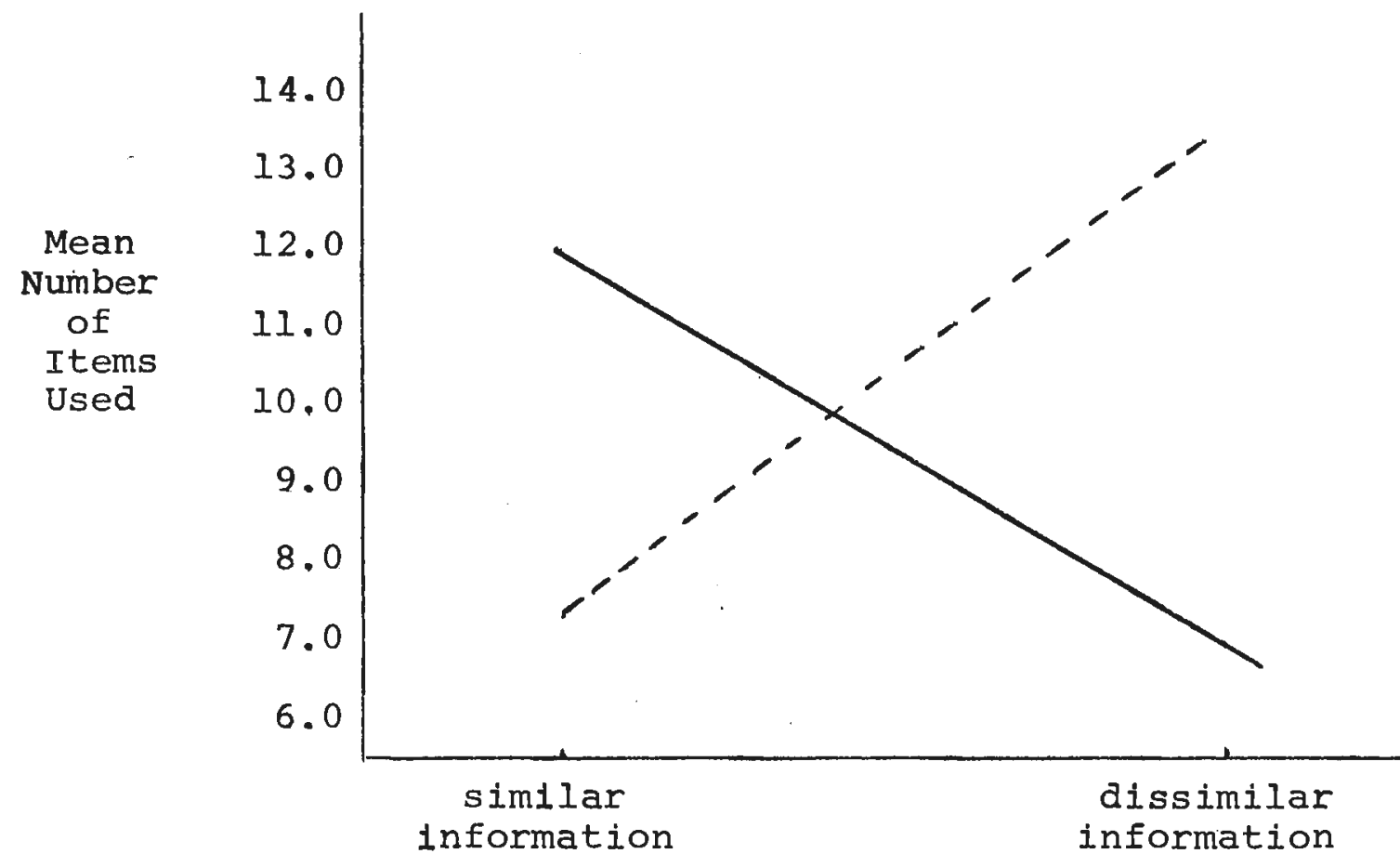

-..- Far Social Distance

- Close Social Distance

Fig. 1

The effect of social distance on information seeking behavior at two conditions of similarity. 


\begin{abstract}
TABLE IV
MAIN EFFECTS OF SIMILARITY

AT BOTH LEVELS OF SOCIAL DISTANCE
\end{abstract}

\section{Source \\ Similarity at} the Level of

Social Closeness

Similarity at the Level of

Social Distance

\section{Error}

(D $x$ Subjects)

493.92

38

$1 \quad 553.60$

$42 \cdot 59^{*}$ *

768.80

1

768.80

$59.14^{* *}$

F

Total

1816.32

40

$\star \star \quad p<.01$ 

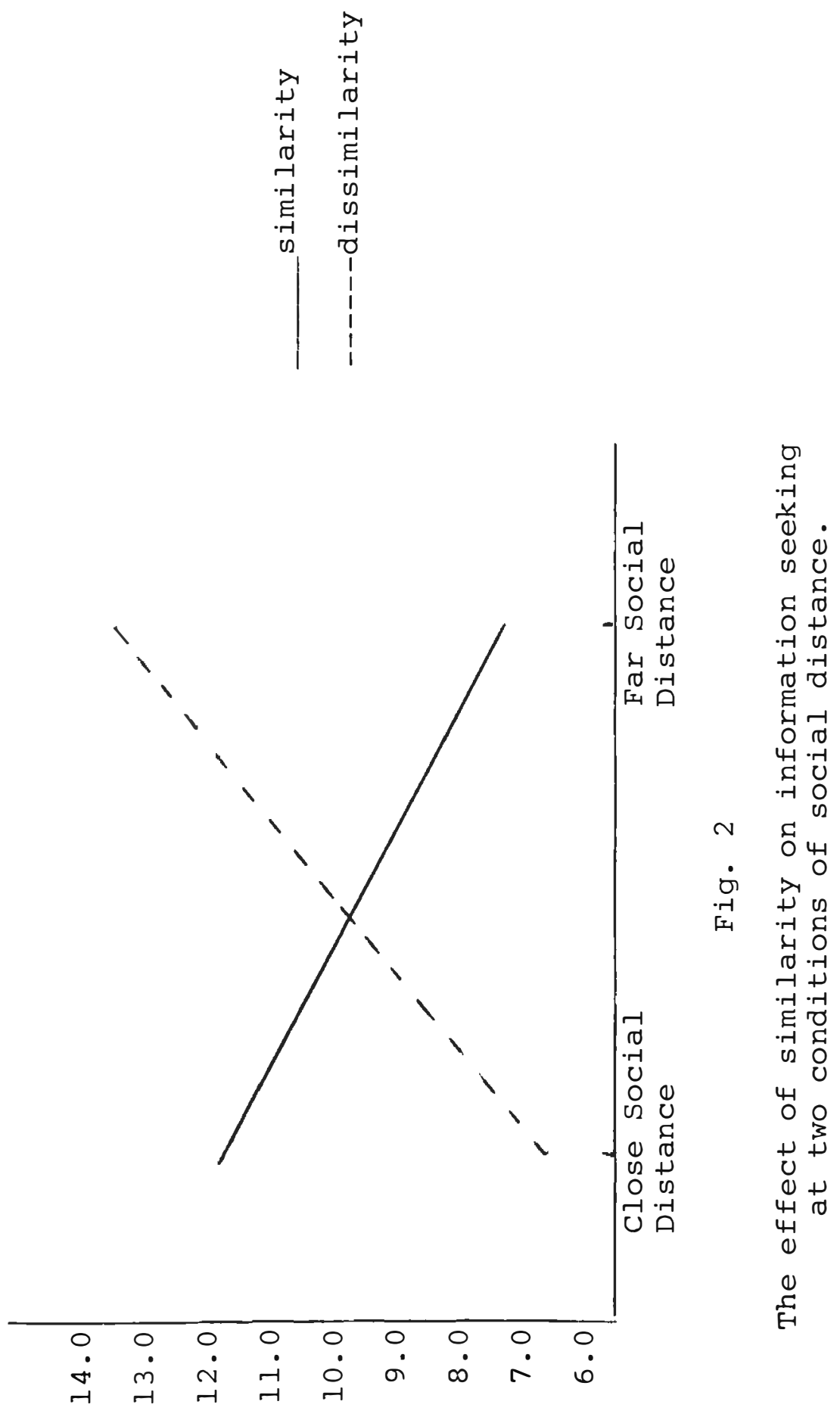

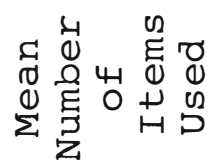




\section{TABLE V}

MAIN EFFECTS OF ITEM IMPORTANCE

AT BOTH LEVELS OF SOCIAL DISTANCE

Source

at the Level of

Social Closeness

168.20

$1 \quad 168.20$

$39.55^{* *}$

Item Importance at the Level of Social Distance

$$
352.80
$$

1

352.80

$82.96^{\star \star}$

\section{Error}

( I x Subjects)

161.60

38

4.25

Total

682.60

40

** $\mathrm{p}<01$




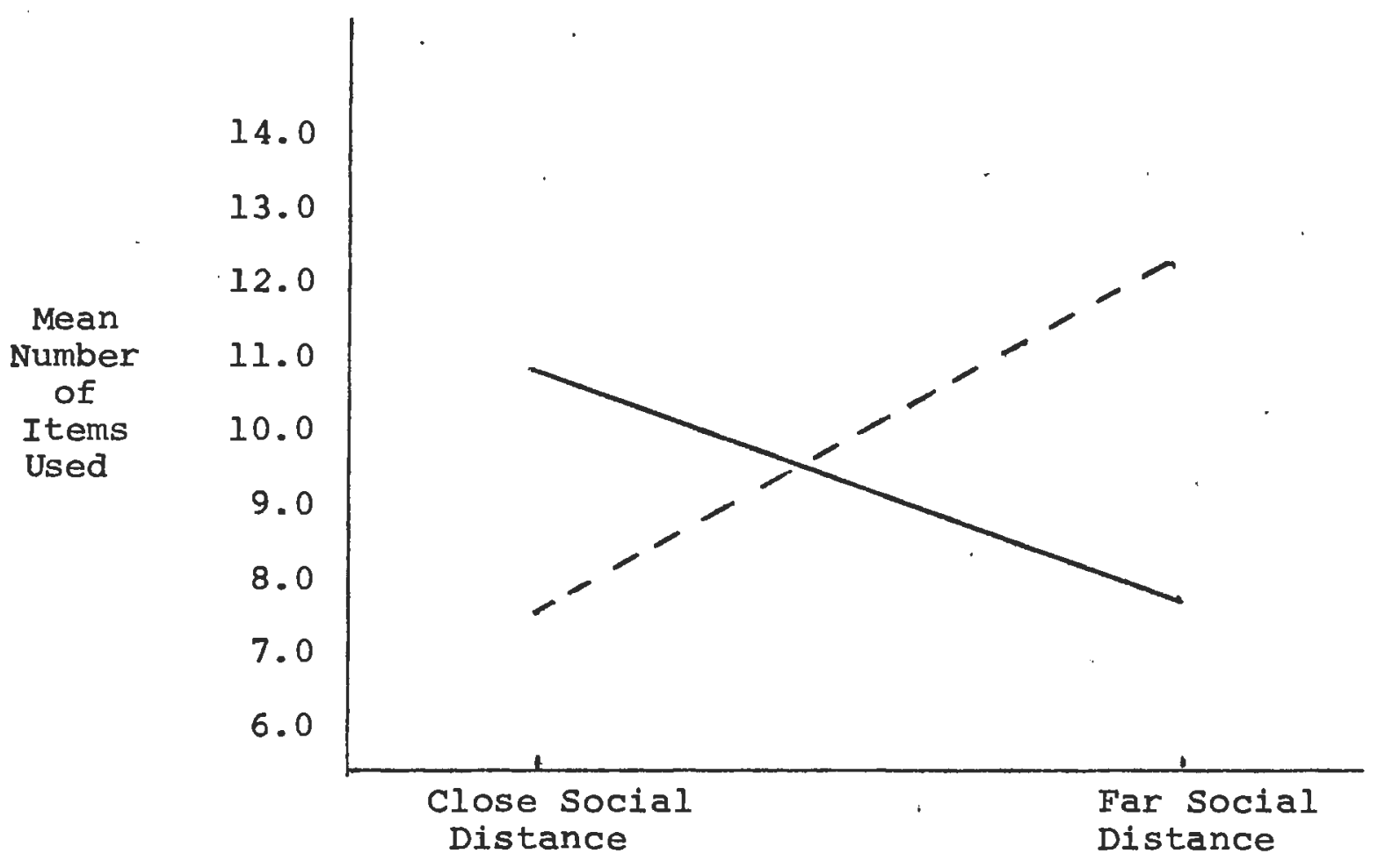

High Importance Items

---Low Importance Items

Fig. 3

The effect of item importance on information seeking at two conditions of social distance. 
TABLE VI

MAIN EFFECTS OF SOCIAL DISTANCE

AT BOTH LEVELS OF ITEM IMPORTANCE

\begin{tabular}{lcccc}
\hline \hline Source & SS & df & MS & F \\
\hline $\begin{array}{l}\text { Social Distance } \\
\text { at the Level of } \\
\text { High Importance }\end{array}$ & 135.20 & 1 & 135.20 & $9.56^{* *}$ \\
$\begin{array}{l}\text { Social Distance } \\
\text { at the Level of } \\
\text { Low Importance }\end{array}$ & 387.20 & 1 & 387.20 & $27.37^{* *}$ \\
$\begin{array}{l}\text { Error } \\
\text { (pooled: Sub. w. } \\
\text { gps. \& I x Subjects) }\end{array}$ & & & \\
\hline \\
Total
\end{tabular}

** $\mathrm{p}<.01$ 


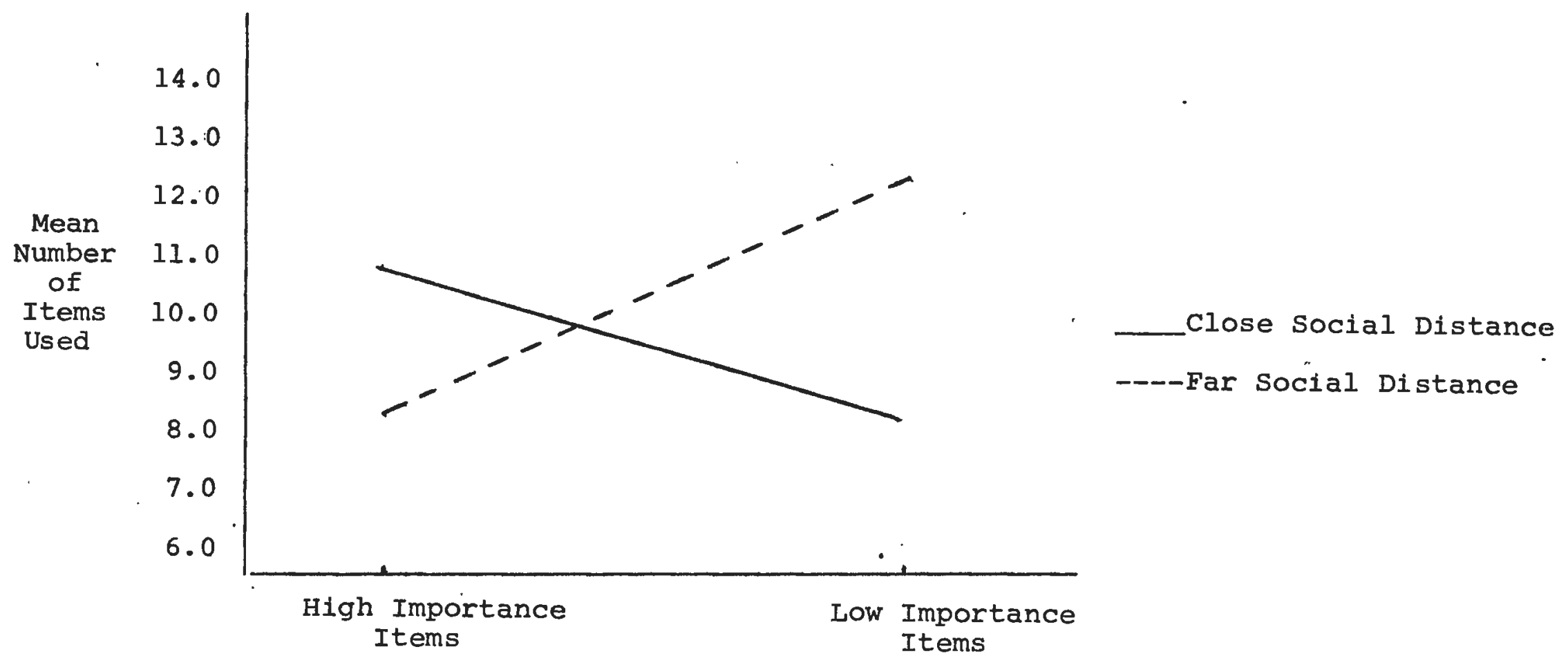

Fig. 4

The effect of social distance on information seeking at two conditions of item importance. 
TABLE VII

MAIN EFFECTS OF ITEM IMPORTANCE

AT BOTH LEVELS OF SIMILARITY

\begin{tabular}{llllll}
\hline Source & SS & df & MS & F
\end{tabular}

Item Importance

at the Level of

similarity

2.11

1

2.11

$.55^{*} *$

Item Importance

at the Level of

Dissimilarity

46.51

1

46.51

$12.08^{* *}$

\section{Error}

(pooled: I x Sub. \& 293.16

76

293.16

I $\mathrm{X}$ D $\mathrm{x}$ Subjects)

Total

341.78

78

${ }^{*} \mathrm{p}<.01$ 


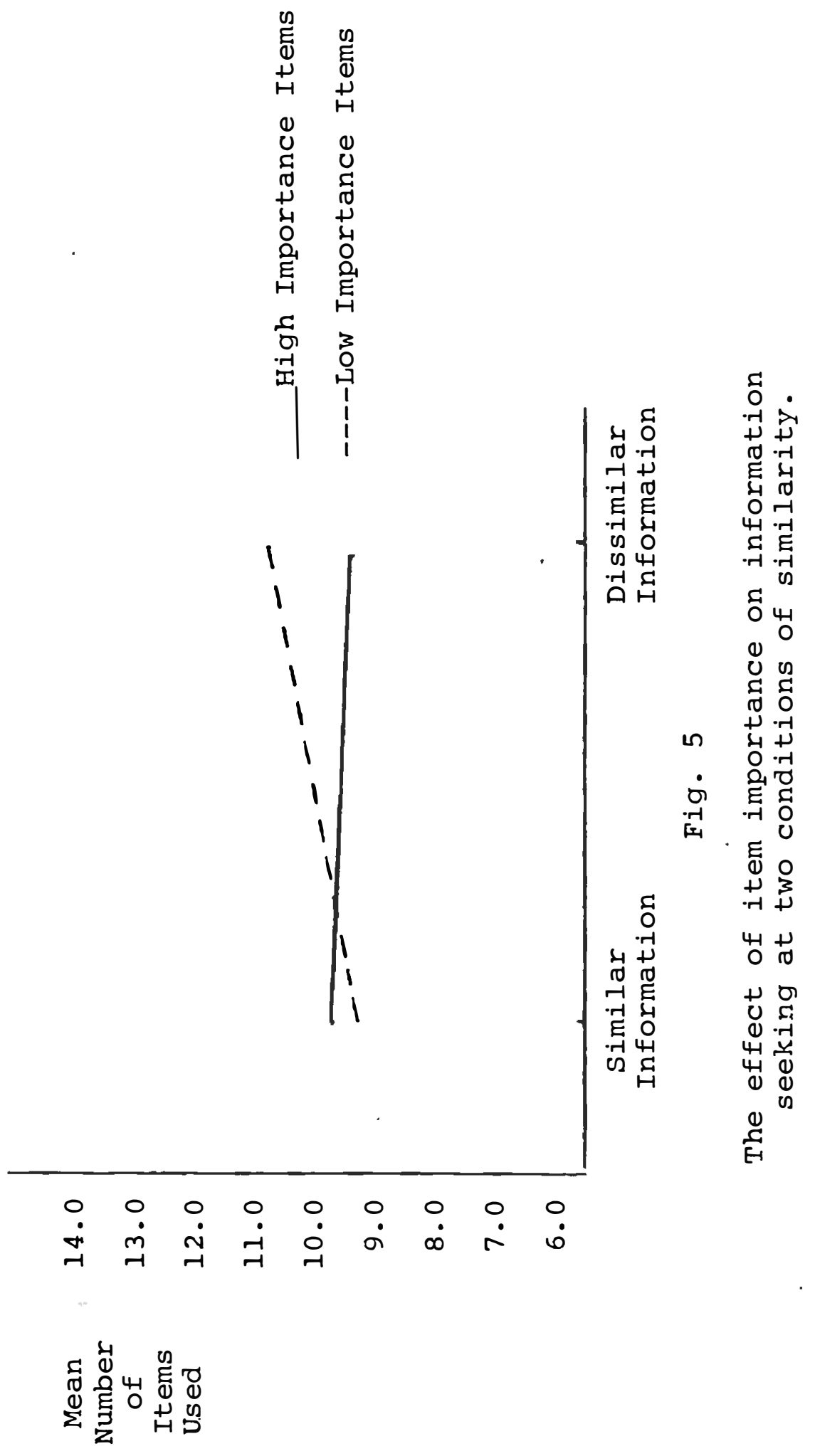


TABLE VIII

MAIN EFFECTS OF ITEM SIMILARITY

AT BOTH LEVELS OF ITEM IMPORTANCE

\begin{tabular}{|c|c|c|c|c|}
\hline Source & SS & $d f$ & MS & $\mathrm{F}$ \\
\hline $\begin{array}{l}\text { Item Similarity } \\
\text { at the Level } \\
\text { of High Importance }\end{array}$ & 4.05 & 1 & 4.05 & $.49^{\star *}$ \\
\hline $\begin{array}{l}\text { Item Similarity at } \\
\text { the Level, of Low } \\
\text { Importance }\end{array}$ & 39.20 & 1 & 39.20 & $4.76^{\star \star}$ \\
\hline $\begin{array}{l}\text { Error } \\
\text { (pooled: D x Sub. \& } \\
\text { I } x \text { D X Subjects) }\end{array}$ & 625.49 & 76 & 8.23 & 9 \\
\hline Total & 668.74 & 78 & & \\
\hline
\end{tabular}

** $\mathrm{p}<.05$ 


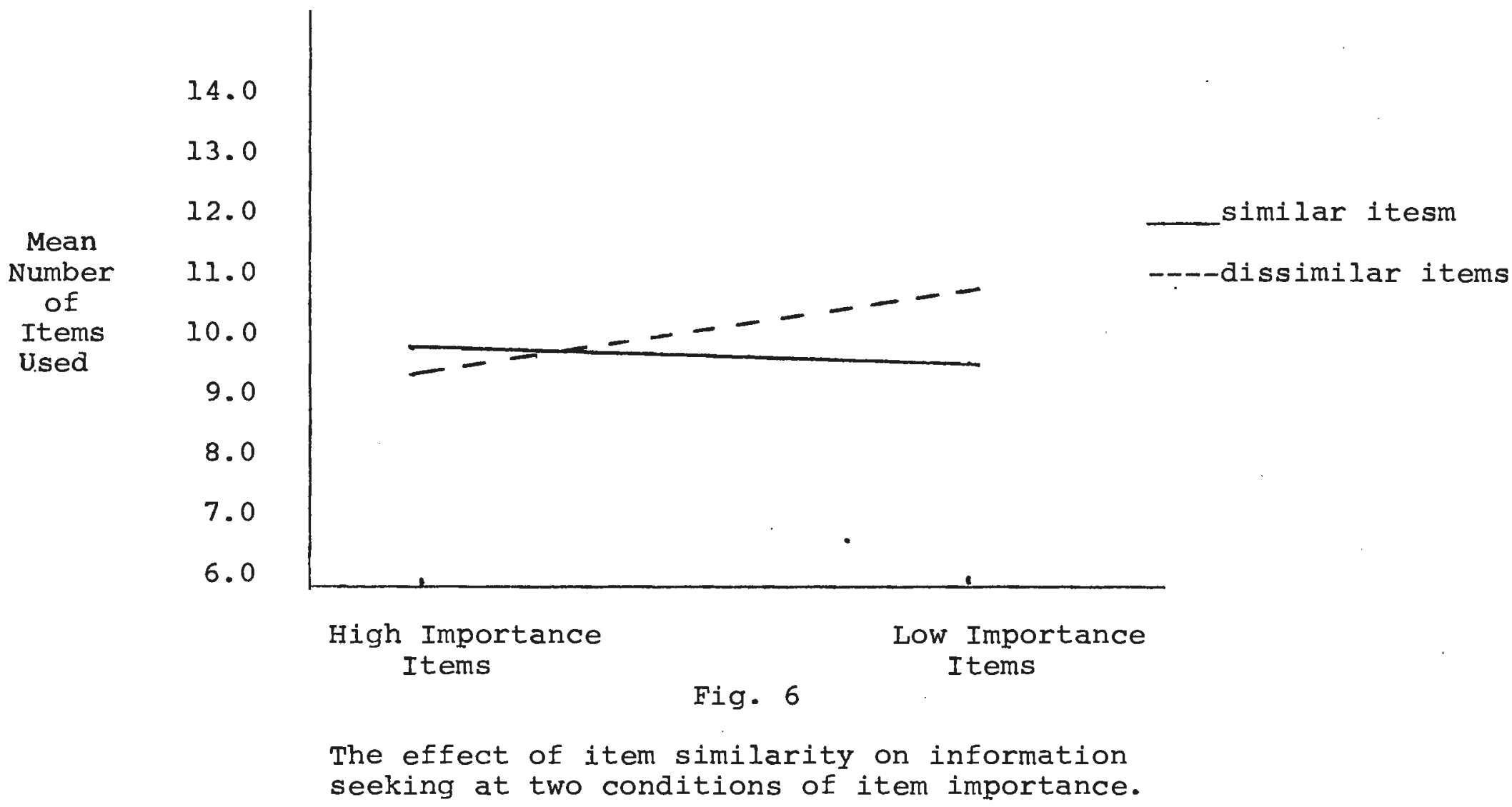


TABLE IX

MEAN NUMBER OF ITEMS USED BY SUBJECTS

IN SEEKING INFORMATION UNDER

DIFFERENT INFORMATION CONDITIONS

Mean

Number of

Items Used
Standard

Deviation

Condition

11.85

$4 \cdot 46$

Information

Dissimilar

Information

High Importance

Information

Low Importance

Information

DISTANT SOCIAL SITUATION

Similar

Information

Dissimilar

Information

13.23

4.23

High Importance

Information

8.08

3.49

Low Importance

Information
7.03

2.26

3.84

5.11
4.28
7.78

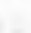


1. high importance similar items

2. Low importance similar items

3. high importance dissimilar items

4. low importance dissimilar items

5. overall level of information seeking

6. Rigidity Scale

7. Locus of Control scale

8. Self Acceptance Scale

No significant correlations ( $p$.05) were found between the personality characteristics measured and the information seeking styles.

There were significant correlations ( $p$.01) found for the way individuals sought information under different information conditions. At close social distances significant correlations were found for the way individuals sought information at different levels of similarity. At far social distances significant correlations were found for the way individuals sought information at different levels of similarity as well as different levels of item importance.

\section{Interpersonal Attraction}

Subjects were given the opportunity to indicate on a separate form whether or not they accepted or rejected the individual for whom they sought information. In general, subjects accepted similar individuals and rejected dissimilar individuals. However, in distant social situations and under conditions of low item importance, $50 \%$ of the dissimilar individuals were accepted (see Table XII). 
TABLE $X$

CORRELATIONS BETWEEN LEVELS OF INFORMATION SEEKING AT CLOSE SOCIAL DISTANCE AND SCORES ON PERSONALITY TESTS

\begin{tabular}{|c|c|c|c|c|c|c|c|c|}
\hline & & & & VARIABI & NUMBEF & & & \\
\hline & 1 & 2 & 3 & 4 & 5 & 6 & 7 & 8 \\
\hline 1 & 1.00 & $0.59^{* *}$ & 0.19 & 0.22 & $0.75^{\star \star}$ & 0.25 & -0.42 & -0.19 \\
\hline 2 & & 1.00 & -0.05 & 0.22 & $0.64^{\star \star}$ & 0.21 & -0.34 & -0.19 \\
\hline 3 & & & 1.00 & $0.77^{* *}$ & $0.66^{* *}$ & -0.22 & 0.13 & -0.28 \\
\hline 4 & & & & 1.00 & $0.75^{* *}$ & 0.02 & 0.17 & -0.19 \\
\hline 5 & & & & & 1.00 & 0.10 & -0.19 & -0.30 \\
\hline 6 & & & & & & 1.00 & -0.11 & $-0.53^{\star}$ \\
\hline 7 & & & & & & & 1.00 & 0.07 \\
\hline 8 & & & & & & & & 1.00 \\
\hline
\end{tabular}

* $\mathrm{p}<.05 \quad * * \mathrm{p}<.01$ 
TABLE XI

CORRELATIONS BETWEEN LEVELS OF INFORMATION SEEKING AT FAR SOCIAL DISTANCE AND SCORES ON PERSONALITY TESTS

\begin{tabular}{|c|c|c|c|c|c|c|c|c|}
\hline \multicolumn{9}{|c|}{ VARIABLE NUMBER } \\
\hline & 1 & 2 & 3 & 4 & 5 & 6 & 7 & 8 \\
\hline 1 & 1.00 & $0.61 * *$ & $0.71^{* \star}$ & $0.64^{* \star}$ & $0.86^{* *}$ & -0.11 & 0.03 & 0.25 \\
\hline 2 & & 1.00 & $0.67^{* *}$ & 0.25 & $0.67^{* *}$ & -0.13 & 0.05 & 0.05 \\
\hline 3 & & & 1.00 & $0.66^{* *}$ & $0.92^{\star \star}$ & -0.00 & 0.18 & 0.28 \\
\hline 4 & & & & 1.00 & $0.84^{* *}$ & -0.02 & 0.23 & 0.18 \\
\hline 5 & & & & & 1.00 & -0.06 & 0.17 & 0.24 \\
\hline 6 & & & & & & 1.00 & -0.22 & 0.25 \\
\hline 7 & & & & & & & 1.00 & -0.19 \\
\hline 8 & & i & & & & & & 1.00 \\
\hline
\end{tabular}

$* * \mathrm{p}<.01$ 
TABLE XII

PERCENTAGE OF ACCEPTANCES AND REJECTIONS

UNDER DIFFERENT INFORMATION CONDITIONS

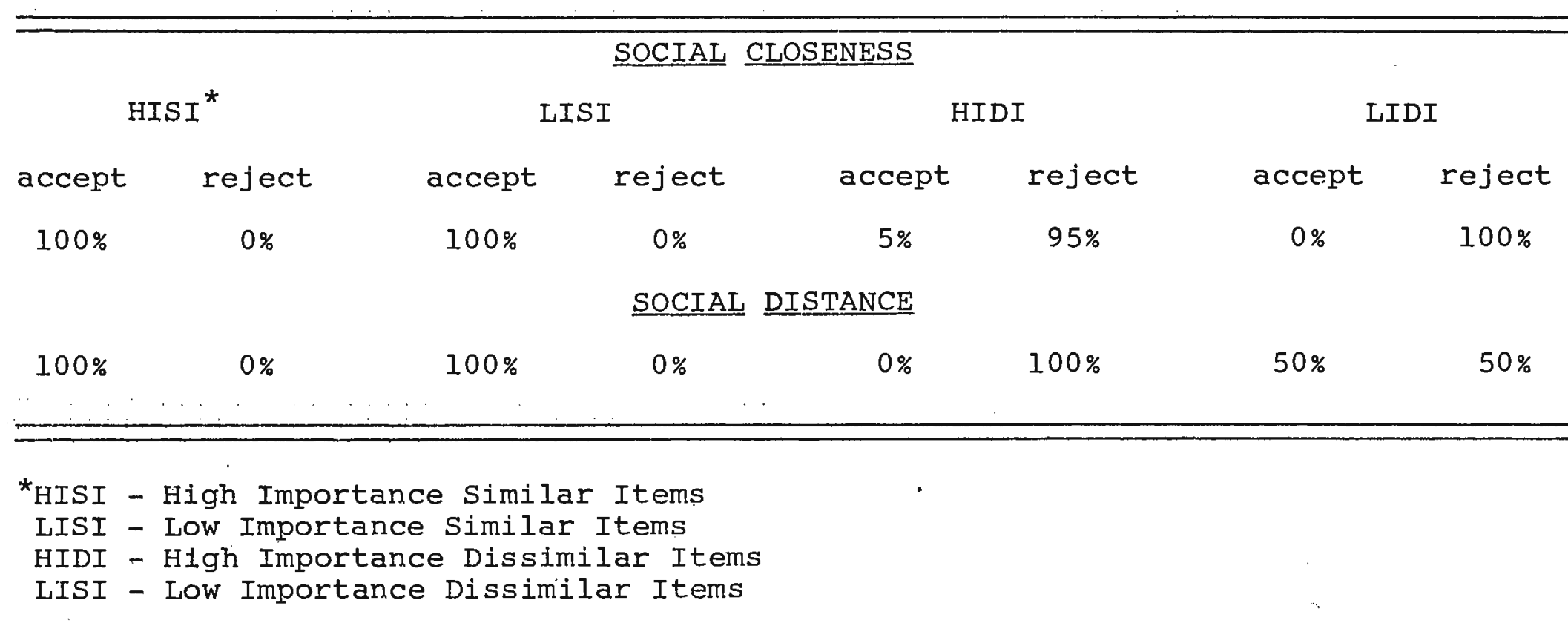




\section{DISCUSSION AND IMPLICATIONS}

In the initial Information seeking study (Sternlight, 1974) the data indicated not only that similarity had a significant effect on information seeking but also that its effect was to increase the amount of information subjects would use to make decisions concerning other individuals. However, other variables of information (other than whether it was coming from a black or white person) were not present. The present study suggests that all the variables studied (similarity, importance, social distance) have a significant effect on information seeking. But one cannot talk about the main effects in the abstract, since the changes in information seeking depend on combinations of the variables. That is, information seeking appears to be a multivariate, interactive phenomenon. The interactive effects are quite clear and thus, the present study continues to support the notion that information seeking is lawful behavior.

The interaction character of each variable will be discussed.

\section{Similarity and Information Seeking}

Similarity results in increased information seeking at close social distances and decreased information seeking at far social distances (see Fig. 2). Dissimilarity results in decreased information seeking at close social distances and 
increased information seeking at far social distances. Thus similarity acts to maintain engagement and interest in close social situations and dissimilarity tends to "shut down" interest and continued learning. Dissimilarity tends to maintain engagement and interest in far social situations while similarity tends to "shut down" interest and continued learning.

The similarity of the information has little effect on information seeking if the information is of high importance (see Fig. 6). That is, whatever decisions we will make, we will use the same amount of information whether it is similar or dissimilar, if the information is of high importance. Engagement and continued interest cannot be altered by altering the similarity of the information if it is of high importance. On the other hand similarity decreases information and dissimilarity increases information seeking if the information is of low importance.

Social Distance and Information Seeking

Close social distances act to increase information seeking and far social distances act to decrease information seeking if the information is similar (see Fig. 1). Close social distances act to decrease information seeking while far social distances act to increase information seeking if the information is dissimilar.

close social distances act to increase information seeking while far social distances act to decrease information 
seeking if the information has high importance value (see Fig. 4). Close social distance acts to decrease information seeking while far social distance acts to increase information seeking if the information has low importance.

\section{Item Importance and Information Seeking}

There is no significant effect of item importance if the information is similar to the seeker (see Fig. 5). However, high importance acts to decrease information seeking while low importance acts to increase information seeking if the information is dissimilar to the seeker.

The overall results are summarized in Table XIII. More simply put, if one were to do some social engineering in order to increase interest and communications between whites and blacks, for example, and if one were dealing with black-white groups who were dissimilar to each other, the optimal arrangement (according to the current data) would be to have one group watch a television interview of the other group on subjects of low importance. On the othe hand, if the black-white groups were similar to each other, placing them together in ongoing groups which discussed issues of high importance would result in increased information seeking and thus increased interest and learning.

More generally put, individuals in close social groups will become more interested in one another if they are sharing similar attitudes and feelings about important issues and individuals who are related to one another at great social 
TABLE XIII

INTERACTIVE EFFECT OF SIMILARITY, ITEM IMPORTANCE AND SOCIAL DISTANCE ON INFORMATION SEEKING

\begin{tabular}{lcccc}
\hline & $\begin{array}{c}\text { Close } \\
\text { Social } \\
\text { Distance }\end{array}$ & $\begin{array}{c}\text { Far } \\
\text { Social } \\
\text { Distance }\end{array}$ & $\begin{array}{c}\text { High Item } \\
\text { Importance }\end{array}$ & $\begin{array}{c}\text { Low Item } \\
\text { Importance }\end{array}$ \\
SIMIIARITY & increase & decrease & no effect & decrease \\
DISSIMILARITY & decrease & increase & no effect & increase \\
HI IMPORTANCE & increase & decrease & & \\
LOW IMPORTANCE & decrease & increase & \\
\hline \hline
\end{tabular}


distances will become more interested in one another if exposed to unimportant differences in attittude and feeling.

One can speculate as to the theoretical implications of the results which have been presented. It is not so much that the data support the following speculation as it is that they lead one to this kind of thinking. The results seem to indicate that in close situations, where we make the most intimate kinds of investment, we want other individuals to be like us. Similarity seems to act on information seeking much like a positive reinforcer. It is as if our safety and well being in close social situation- are determined by how well we believe we "fit" with the attitudes and beliefs around us. This is certainly consistent with what one observes emperically in the interactions of people who are socially close. Husbands and wives, for example, will argue over points in attitude and belief which would pass unnoticed between people not so closely related. In close social situations it makes us feel good to know that we are agreed with and when we learn of agreement we want to know more and more. on the other hand, in close social situations differences in attitude and belief seem to act as aversive stimuli to information seeking. We seem to want to know as little as possible about differences and dissimilarity in our initmates and prevent ourselves from knowing by closing our minds and interest to these discrepancies between ourselves and people for whom we are closely related socially. It is as if we feel bad when we discover that socially important people are 
different in any way from ourselves.

The result is that we come to know more and more about the similarity in people with whom we have close relationships andless and less about our differences. One of the effects of this might be to reality so that we come to believe that our important social groups are much more homogeneous than they probably are. Ultimately these groups might come to be more homogeneous than they would have been if information seeking were the same for dissimilarity as it is for similarity.

Thus, we quickly come to identify a socially close "we" on the basis of similarity. The dissimilar individuals become a "they," outsiders for whom we in fact know little because we do not seek much. And since we know little it becomes easy to lump people into stereotypes.

Socially distant situations are quite a different matter. We do not appear to be as concerned with out own identity and searching to see how well we fit. Social distances seem to "buffer" us against the fear we will be different (and perhaps rejected) from other people. In these situations it seems that we seek information for its novelty value. At a safe distance we seem quite interested in different beliefs and attitudes and these take on the qualities of a positive reinforcer for information seeking. In fact, if we are not really involved and are not seeking to "fit" into a social group, we shut down to similar information as if we are simply bored. 
Another way of saying this is that at close social distances similarity has the instrumental value of telling us how well we "fit." When we are socially distant similarity has little instrumental value. In these situations dissimilarity has less personal repercussion so that we are more safe in exploring different attitudes and beliefs. Dissimilarity can offer the instrumental value here of opening new horizons and life styles to us all. The speculative suggestion is that new ideas most effectively come from socially distant information sources. If this is true then a parent, for example, would not become more accepting of pre-marital living together in young people by learning that their children wish to do this. But they would modify rejecting attitudes toward this behavior by learning that many young people, whom they are not socially close to, engage in this new life style, in a way approved of by many adults they are not socailly close to. Watching a television program, positively disposed to alternate life styles might result in greater openness and interest then hearing the same information from a son or daughter.

In sum, the speculative ideas which are being proposed to account for the data of the present study are as follows:

In close social situations information is used for its value in estimating how well one's attitudes "fit" with others. Similarity increases one's sense of acceptance and 
belonging and acts much like a positive reinforcement for information seeking. Dissimilarity increases one's discomfort and sense of acceptance and acts as an aversive stimulus for information seeking.

At far social distances the issue of belonging does not appear to be salient and one's comfort with dissimilarity seems increased. It is as if dissimilar information is used for its novelty value. Dissimilarity acts as a positive reinforcement for information seeking and individuals respond to similar information by seeking less.

Most important is that the present study supports the notion that information seeking is lawful behavior. It strongly suggests that we do not seek information simply for its intrinsic value but rather in certain predictable ways which are dependent on at least the similarity of the information, the importance of the information and the social context in which we seek. The current data have application not only in helping to understand the differences in the way populations seek information but also in offering ways in which the information seeking behavior of people can be altered.

Beside the speculative issues which the present study raises there are several questions in the existing psychological literature for which the present study offers new ideas.

Researchers have been struggling to understand the relationship between similarity and interpersonal attraction for over a hundred years. From the work of Galton in 1870 to 
the work of Griffitt in 1974 social scientists have repeatedly observed the strong relationship between interpersonal attraction and similarity and offered a variety of explanations for the way in which this relationship operates. The present study offers a simple explanation for this relationship. It suggests that similarity has the effect of causing increased information seeking and thus increased maintenance of contact and interest. As a result one wants to spend more time with and has more interest in, a similar individual. Dissimilarity shuts down information seeking and thus contact and interest. What Kirkpatrick and Stone (1935) spoke of as "attraction" may be nothing more than an increase in the desire for more information. As Newcomb's studies $(1956,1961)$ pointed out, learning comes before liking. Lott and Lott (1965) note the same relationship for group cohesiveness and similarity of attitude. Highly cohesive groups are groups with high similarity of attitude. It has also been shown that in the group psychotherapy process (Yalom, 1970), groups become more cohesive as similarities between members are shared. The present study suggests that all these phenomena can be understood at the basic level of information seeking.

Another area for which the present study offers clear answers involves work Byrne and Nelson (1964) did with item importance and interpersonal attraction. This study, described in the introduction, was based on the assumption that the importance of the items had an effect on the way people 
made judgments about other individuals. They presented some subjects with information of high importance and some subjects with information of low importance. For both groups of subjects the information was varied on the similarity-dissimilarity dimension and it was found that information importance did not effect the way attraction judgments were made. Byrne and Nelson openly shared their surprise at these results. The present study shows that under conditions of similarity of information the importance variable is not statistically significant. It is not at all surprising that Byrne and Nelson go their results. The importance variable is significant when it is varied along with social distance. The present study suggests that Byrne and Nelson would have found positive results if some of their subjects were evaluating at close social distance and some at far social distance. More specifically, 50\% of the dissimilar individuals who were rejected on the basis of low important items at close social distances would have been accepted at far social distances. The present study also offers new ideas for some of the notions in Festinger's cognitive dissonance theory (1957). Many of the concepts have been criticized methodologically because of their "construct" nature. That is, they are diffusely and theoretically defined (Chapanis \& Chapanis, 1964). A good example of this is the idea of reducing postdecisional dissonance. According to Knox and Inkster (1968), "A favorite technique is to change cognitions in such a manner 
as to increase the attractive ness of the chosen alternative relative to the unchosen alternative(s)." Knox and Inkster proceed to demonstrate that a decision is more favorably evaluated after some time has elapsed. However, they never consider how this increase in attractiveness occurs through the cognitive process.

The data in the present study suggest that people are able to "shut down" to dissimilar information by termination of the information seeking process. Dissimilar in this case is used for information which is discrepant or contrary to that which supports the chosen view. Thus dissonance is reduced because there is a "shut down" to information which is contrary to that which would support the view of the individual. The less discrepant information that is sought, the more positive the chosen veiw becomes. Dissonance itself may be nothing more than a high level of dissimilar information seeking. When one begins to deal with an idea it is in the abstract, "out there" not part of one's self. The analogy which is being drawn is that at this stage of attitude formation ideas are responded to as "socially distant." Under these conditions the present data suggest that individuals do seek high levels of dissimilar information. As the individual continues to evaluate the idea he begins to learn toward one to another view. At this point the process becomes more personalized and the more one or another belief about the idea is formulated, the more the individual becomes personally involved in seeing the idea as part of his own identity. At this point 
the process of information seeking may be seen to be occuring as like that of a socially close situation. The process of seeking dissimilar information terminates and only more and more similar information (supporting ideas) is sought. In this way dissonance (dissimilarity) is reduced and the attitude or belief which the individual has become committed to increases its attractiveness.

\section{Interpersonal Attraction}

In the previous study (Sternlight, 1972) the data indicated that acceptance or rejection of another individual was a function of similarity. That is, individuals who were similar to the seeker were accepted and individuals who were dissimilar to the seeker were rejected. This notion is consistent with the majority of the social psychology research in the area of interpersonal attraction (Byrne 1971). However, the present study suggests that the acceptance or rejection of an individual is more complicated. The data indicate that the acceptance or rejection of an individual is also an interactive effect. Fifty percent of the subjects in the present study accepted dissimilar individuals when the dissimilar information was received under conditions of large social distance and low importance. Thus, there are conditions when a good percentage of subjects will accept dissimilar individuals. In other words, in order to maximize the acceptance of dissimilar individuals they must be presented under conditions 
of large social distance with dissimilarity in low importance issues.

Personality and Information Seeking

No correlations were found between the personality tests which were given and the level of information seeking. However, there were significant correlations found for the way individuals sought information at different levels of similarity and different levels of item importance. This suggests that there are consistent individual differences for information seeking. behavior. Subjects who sought comparatively high amounts of one kind of information sought comparatively high amounts of other kinds of information. And subject who sought comparatively low amounts of one kind of information sought comparatively low amounts of other kinds of information. Thus, there do seem to be "styles" of information seeking consistent within individuals. If these "styles" are due to some personality characteristic, then either the critical characteristics were not included in the measures selected or the personality tests which were used do not measure the characteristics they are reported to measure.

Another explanation is that information seeking is not a function of personalit characteristics but rather a result of the way the brain functions as a cognitive machine. Differences in information seeking are a reflection of different cognitive sensitivities. One way to conceptualize 
this without invoking personality would be to say that each bit of information is used to establish the probability that something is or is not true. For individual one, a certain number of bits result in a probability value great enough to make a decision. For individual two, the only aifference is that all bits of intormation nave, in general, a lower probability value so that it takes more bits to reach a probability great enough to make a decision. That is, there is a normal distribution within the general population, of probability sensitivities to individual bits of intormation. The argument may be circular since it is not unreasonable to assume that even if this were true it would result, secondarily, in personality differences.

It should be pointed out that individual differences for information seeking are not present in close social situations when the information is varied along the dimension of item importance. This is consistent with the great body of literature on interpersonal attraction which presents the view that in close social situations the most important factor is similarity and that this has an overriding. impact on the way people make judgments. 


\section{SUMMARY}

The purpose of this study was to investigate the effects of information similarity, information importance and social distance on information seeking behavior. Information seeking behavior is defined here as the amount of information an individual requires in order to bring closure to an information search involving the acceptance or rejection of a person on the basis of their expressed attitudes.

Previous research indicated that similarity of information was a powerful determinant of the amount of information individuals would require to make decisions about other individuals. The data suggested that the variations in information seeking, which were caused by alterations in the similarity of that information, were lawful. However, other variables had not been explored and the simplicity of the design did not allow for any observation of complex interactive effects.

To test the effects of other variables, subjects were asked to seek as much or as little information as they required to make decisions about accepting or rejecting other individuals under conditions of social distance, social closeness, similarity of information, dissimilarity of information, high importance information and low importance information. To accomplish this, attitude questionnaires were 
given to subjects and on the basis of their responses individual protocols were created so that they would appear similar or dissimilar and of high importance or of low importance. The social closeness situation was represented by the instruction to accept or reject an individual as a roommate and the social distance situation was represented by the instruction to accept or reject an individual simply as a member of the general community. The amount of information used under the different conditions was analyzed using a three way analysis of variance.

It was found that the amount of information which subjects required depended on the interaction of each variable with the other. Statistically significant increases in information seeking were found under conditions of similar information and social distance, high importance information and social closeness, low importance information and social distance, dissimilar and low importance information. Statistically significant decreases in information seeking were found under conditions of dissimilar information and social closeness, similar information and social distance, high importance information and social distance, low importance information and social closeness, similar low importance information. Some discussion was presented on the utilization of this data to maximize interest and learning between individuals and groups under different conditions. 
Previous research also indicated that for the most part seekers accepted or rejected inaividuals on the basis of similarity. That is, similar individuals were uniformly accepted and dissimilar individuals were uniformly rejected. With the current addition of more representative variables it was found that this, too, is an interactive phenomenon. That is, under conditions of far social distance and for items of information which were of low importance, half the seekers accepted dissimilar individuals. Under other conditions the acceptance and rejection trends were the same as those which appeared in the previous research: Acceptance on the basis of similarity, rejection on the basis of dissimilarity.

Finally, some initial exploration was conducted to see if there were personality characteristics which were responsible for variations in the individual levels of information seeking. The personality characteristics which were chosen were rigidity, self acceptance and locus of control. Personality tests which measure these characteristics were given to the sample and correlation studies were carried out between personality test scores and the information seeking scores at all levels. No correlation was found between the test scores and information seeking level. However, there were significant correlations found for the way individuals sought information under different information conditions. This suggests that there are consistent individual differences. 
The present study supports the finding that information seeking behavior is lawful and specifies the variations under different conditions. 


\section{BIBLIOGRAPHY}

Aristotle. The Rhetoric. New York: Appleton-CenturyCrofts, 1932 .

Berger, E., "The Relations between Expressed Acceptance of Self and Expressed Acceptance of Others," Journal of Abnormal and Social psychology, 1952, 47, 778-782.

Bogardus, E. S. Immigration and Race Attitudes. Boston: Heath, 1928.

Byrne, D., "Authoritarianism and Response to Attitude Similarity-Dissimilarity," Journal of Social Psychology, $1965, \underline{66}, 251-256$.

Byrne, D. The Attraction Paradiam. New York: Academic Press, 1971 .

Byrne, D. Personality and Psychopathology. New York: Academic Press, 1971.

Byrne, D., "Response to Attitude Similarity-Dissimilarity as a Function of Affiliation Need," Journal of Personality, 1962, 30, 164-177.

Byrne, D., O. London, and w. Griffitt, "The Effect of Topic Importance and Attitude Similarity-Dissimilarity on Attraction in an Intrastranger Design," Psychonomic Science, 1968, 11, 303-304.

Byrne, D. and C. McGraw, "Interpersonal Attraction Toward Negroes," Human Relations, 1964, 17, 201-213.

Byrne, D. and D. Nelson, "Attraction as a Function of Attitude Similarity-Dissimilarity: The Effect of Topic Importance," Psychonomic Science, 1964, 1, 93-94.

Byrne, D. and D. Nelson, "The Effect of Topic Importance and Attitude Similarity-Dissimilarity on Attraction in a Multistranger Design," Psychonomic Science, 1965, 3 , $449-450$.

Byrne, D. and T. J. Wong, "Racial Prejudice, Interpersonal Attraction, and Assumed Dissimilarity of Attitudes," Journal of Abnormal and Social Psycholody, 1962, 65 (4), 246-253.

Chapanis, N. P. and A. Chapanis, "Cognitive Dissonance: Five Years Later," Psychological Bulletin, 1964, 61, 1-22. 
Dienstbier, R. A., "A Modified Beliet Theory of Prejudice Emphasizing the Mutual Causality of Racial Prejudice and Anticipated Belief Differences," Psychological Review, 1972, $\underline{79}$ (2), 146-160.

Edwards, A. D. Techniques of Attitude Scale Construction. New York: Appleton-Century-Crott, 1957.

Festinger, L. A Theory of Cognitive Dissonance. Stantord: Stanford University Press, 1957.

Galton, F. Hereditary Genius, An Inquiry into its Laws and Consequences. 1870. (Republished: New York, Horizon, 1952).

Griffitt, W., "Attitude Similarity and Attraction," Foundations of Interpersonal Attraction. Ed. Huston, T. L., New York: Academic Press, 1974.

Griffitt, W. and D. Byrne, "Procedures in the Paradigmatic Study of Attitude Similarity and Attraction," $\mathrm{Re}-$ presentative Research in Social Psychology, 1970, 1, 33-48.

Hays, W. L. Statistics for Psychologists. New York: Holt, Reinhart, and Winston, 1963.

Inski, C. A. and J. É. Robinson, "Belief Similarity Versus Race as Determinants of Reactions to Negroes by Southern White Adolescents: A Further Test of Rokeach's Theory," Journal of Personality and Social Psychology, 1967, 7 (2), 216-221.

Jones, J. M. Prejudice and Racism. Massachusetts: AddisonWestey Publishing Company, 1972.

Kirkpatrick, C. and S. Stone, "Attitude Measurement and the Comparison of Generations," Journal of Applied Psychology, 1935, 19, 564-582.

Knox, R. E. and J. A. Inkster, "Post Decision Dissonance at Post Time," Journal of Personality and Social Psychology, $1968, \underline{8}, 319-323$.

Kogan, N. and M. A. Wallach. Risk Taking a Study in Cognition and Personality. New York: Holt, Rinehart, and Winston, 1964. 
Lott, A. J. and B. E. Lott, "Group Cohesiveness as Interpersonal Attraction: A Review of Relationships with Anticedent and Consequent Variables, "Psychological Bulletin, 1965, 64, 259-309.

Mezei, L., "Perceived Social Pressure as an Explanation of Shifts in the Relative Influence of Race and Belief on Prejudice Across Social Interactions, "Journal of Personality and Social Psychology, 1971.

Morgan, C. L. and H. H. Remmers, "Liberalism and Conservatism of College Students as Affected by the Depression, "School and Society, 1935, 41, 780-784.

Morris, C. Varieties of Human Value. Chicago: University of Chicago Press, 1956 .

Nelson, D., "The Effect of Differential Magnitude of Reinforcement on Interpersonal Attraction," Unpublished Doctoral Dissertation. University of Texas, 1965.

Newcomb, T. M., "The Prediction of Interpersonal Attraction," American Psychologist, 1956, 11, 575-586.

Newcomb, T. A. The Acquaintance Process. New : Holt, Rinehart, and Winston, 1961 .

Rehfisch, J., "Some Scale and Test Correlates of a Personality Rigidity Scale, "Journal of Consulting Psychology, $1958,22,372-374$.

Richardson, H. M., "Community of Values as a Factor in Friendships of College and Adult Women," Journal of Social Psychology, 1940, 11, 303-312.

Robinson, J. E. and C. A. Insko, "Attributed Belief Similairty-Dissimilarity Versus Race as Determinants of Prejudice: A Further Test of Rokeach's Theory," Journal of Experimental Research in Personality. $1969,4,72-77$.

Rokeach, M., "Belief Versus Race as Determinants of Social Distance: Comment on Triandis' Paper," "Journal of Abnormal and Socia1 Psychology, 1961, 62, (1), 187-188.

Rokeach, M. and I. Mezei, "Race and Shared Belief as Factors of Social Choice," Science, 1966, 151, 167-172.

Rokeach, M. P. Smith, and R. I. Evans. Two Kinds of Prejudice or One? in M. Rokeach. The open and closed Mind. $\overline{\text { New }}$ York: Basic Books, $1 \overline{960}$. 
Rotter, J. B., "Generalized Expectancies for Internal Versus External Control of Reinforcement," Psychological Monographs, 1966, 80 (1 whole No. 609).

Schachter, S., "Deviation, Rejection and Communication," Journal of Abnormal and Social Psychology, 1951, 46, $190-207$.

Schooley, M., "Personality Resemblances Among Married Couples," Journal of Abnormal and Social Psychology, $1916,31,340-347$.

Schuster, Elderton, E. M., "The Inheritance of Phýsical Characters," Biometrika, 1906, 5, 460-469.

Stein, D. C., J. A. Hardych, and M. B. Smith, "Race and Belief: An Open and Shut Case," Journal of Personality and Social Psychology, 1965, 1, 281-289.

Sternlight, D., "Information seeking and Prejudice," Unpublished Master's Thesis, University of Rhode Island, 1974 .

Triandis, H. C., "A Note on Rokeach's Theory of Prejudice," Journal of Abnormal and Social Psychology, 1961, 62 (1), $184-186$.

Triandis, H. C. and L. M. Triandis, "Race, Social Class, Religion, and Nationality as Determinants of Social Distance," Journal of Abnormal and Social Psychology, 1960, 61 (1), 110-118.

Vernon, P. E., and G. W. Allport, "A Test for Personal Values," Journal of Abnormal and Social Psychology, $1931, \underline{3}, 231-248$.

Yalom, I. D. The Theory and Practice of Group Psychotherapy. New York: Basic Books, Inc., 1970 .

Young, B. Personality and Psychopathology. Ed. Byrne, D. New York: Academic Press, 1971, 63. 
APPENDICES 
APPENDIX I

INTERPERSONAL JUDGMENT SCALE 
Interpersonal Judqment Scale

Your Name:

\section{Intelligence (check one)}

I believe that this person is very much above average in intelligence.

I believe that this person is above average in intelligence.

I believe that this person is slightly above average in intelligence.

I believe that this person is average in intelligence.

I believe that this person is slightly below average in intelligence.

I believe that this person is below average in intelligence.

I believe that this person is very much below average in intelligence.

2. Knowledge of Current Events (check one)

I believe that this person is very much below average in his (her) knowledge of current events.

I believe that this person is below average is his (her) knowledge of current events.

I believe that this person is slightly below average in his (her) knowledge of current events.

I believe that this person is average in his (her) knowledge of current events.

I believe that this person is slightly above average in his (her) knowledge of current events.

I believe that this person is above average in his (her) knowledge of current events.

I believe that this person is very much above average in his (her) knowledge of current events.

3. Morality (check one)

This person impresses me as being extremely moral.

This person impresses me as being moral.

This person impresses me as being moral to a slight degree.

This person impresses me as being neither particularly moral nor particularly immoral.

This person impresses me as being immoral to a slight degree. 


\section{Morality (continued)}

This person impresses me as being immoral.

This person impresses me as being extremely immoral.

4. Adjustment (check one)

I believe that this person is extremely maladjusted.

I believe that this person is maladjusted.

I believe that this person is maladjusted to a slight degree.

I believe that this person is neither particularly maladjusted nor particularly well adjusted.

I believe that this person is well adjusted to a slight degree.

I believe that this person is well adjusted.

I believe that this person is extremely well adjusted.

5. Personal Feelings (check one)

I feel that I would probably like this person very much.

I feel that I would probably like this person.

I feel that I would probably like this person to a slight degree.

I feel that I would probably neither particularly like nor particularly dislike this person.

I feel that I would probably dislike this person to a slight degree.

I feel that I would probably dislike this person.

I feel that I would probably dislike this person very much.

6. Working Together in an Experiment (check one)

I believe that I would very much dislike working with this person in an experiment.

I believe that I would dislike working with this person in an experiment.

I believe that I would dislike working with this person in an experiment to a slight degree.

I believe that I would neither particularly dislike nor particularly like working with this person in an experiment.

I believe that I would enjoy working with this person in an experiment to a s.light degree.

I believe that I would enjoy working with this person in an experiment.

I believe that I would very much enjoy working with this person in an experiment. 
APPENDIX II

ATTITUDE QUESTIONNAIRE 


\section{Attitude Questionnaire}

Belief in God (check one)

I strongly believe that there is a God.

I believe that there is a God.

I feel that perhaps there is a God.

I feel that perhaps there is no God.

I believe that there is no God.

I strongly believe that there is no God.

War (check one)

I strongly feel that war is sometimes necessary to solve world problems.

I feel that war is sometimes necessary to solve world problems.

I feel that perhaps war is sometimes necessary to solve world problems.

I feel that perhaps war is never necessary to solve world problems.

I feel that war is never necessary to solve world problems.

I strongly feel that war is never necessary to solve world problems.

College Education (check one)

I strongly believe it is very important for a person to have a college education in order to be successful.

I believe it is very important for a person to have a college education in order to be successful.

I believe that perhaps it is very important for a person to have a college education in order to be successful.

I believe that perhaps it is not very important for a person to have a college education in order to be successful.

I believe that it is not very important for a person to have a college education in order to be successful.

I strongly believe that it is not very important for a person to have a college education in order to be successful.

American Way of Life (check one)

I strongly believe that the American way of life is not the best.

I believe that the American way of life is not the best

I feel that perhaps the American way of life is not the best. 
American Way of Life (continued)

I feel that perhaps the American way of life is the best.

I believe that the American way of life is the best.

I strongly believe that the American way of life is the best.

Premarital Sex Relations (check one)

In general, I am very much opposed to premarital sex relations.

In general, I am opposed to premarital sex relations. In general, I am mildly opposed to premarital sex relations.

In general, I am mildly in favor of premarital sex relations.

In general, I am in favor of premarital sex relations. In general, I am very much in favor of premarital sex relations.

Preparedness for War (check one)

I strongly believe that preparedness for war will not tend to precipitate war.

I believe that preparedness for war will not tend to precipitate war.

I feel that perhaps preparedness for war will not tend to precipitate war.

I feel that perhaps preparedness for war will tend to precipitate war.

I believe that preparedness for war will tend to precipitate war.

I strongly believe that preparedness for war will tend to precipitate war.

Integration in Public schools (check one)

Racial integration in public schools is a mistake, and I am very much against it.

Racial integration in public schools is a mistake, and I am against it.

Racial integration in public schools is a mistake, and I am mildly against it.

Racial integration in public schools is a good plan, and I am mildly in favor of it.

Racial integration in public schools is a good plan, and I am in favor of it.

Racial integration in public schools is a good plan, and I am very much in favor of it. 
Nuclear Arms Race (check one)

I am very much opposed to the federal government's buildup of nuclear arms.

I am opposed to the federal government's buildup of nuclear arms.

I am mildly opposed to the federal government's buildup of nuclear arms.

I am mildly in favor of the federal government's buildup of nuclear arms.

I am in favor of the federal government's buildup of nuclear arms.

I am very much in favor of the federal government's buildup of nuclear arms.

One True Religion (check one)

I strongly believe that my church represents the one true religion.

I believe that my church represents the one true religion.

I feel that probably my church represents the one true religion.

I feel that probably no church represents the one true religion.

I believe that no church represents the one true religion.

I strongly believe that no church represents the one true religion.

Red China and the U.N. (check one)

I strongly believe that Red China should not be admitted to the U.N.

I believe that Red China should not be admitted to the U.N.

I feel that perhaps Red China should not be admitted to the U.N.

I feel that perhaps Red China should be admitted to the U.N.

I believe that Red China should be admitted to the U.N. I strongly believe that Red China should be admitted to the U.N.

Socialized Medicine (check one)

I am very much opposed to socialized medicine as it operates in Great Britain.

I am opposed to socialized medicine as it operates in

Great Britain. 
Socialized Medicine (continued)

I am mildly opposed to socialized medicine as it operates in Great Britain.

I am mildy in favor of socialized medicine as it operates in Great Britain.

I am in favor of socialized medicine as it operates in Great Britain.

I am very much in favor of socialized medicine as it - operates in Great Britain.

Divorce (check one)

I am very much opposed to divorce.

I am opposed to divorce.

I am mildly opposed to divorce.

I am mildy in favor of divorce.

I am in favor of divorce.

I am very much in favor of divorce.

Birth Control (check one)

I am very much in favor of most birth control techniques.

I am in favor of most birth control techniques.

I am mildly in favor of most birth control techniques.

I am mildly opposed to most birth control techniques.

I am opposed to most birth control techniques.

I am very much opposed to most birth control techniques.

Professors and Student Needs (check one)

I feel that university professors are completely indi-

fferent to student needs.

I feel that university professors are indifferent to student needs.

I feel that university professors are slightly in-

different to student needs.

I feel that university professors are slightly concerned about student needs.

I feel that university professors are concerned about student needs.

I feel that university professors are very much concerned about student needs.

Acting on Impulse vs. Careful Consideration of Alternatives (check one)

I feel that it is better if people always act on impulse.

I feel that it is better if people usually act on impulse.

I feel that it is better if people often act on impulse. 
Acting on Impulse vs. Careful Consideration of Alternatives (continued)

I feel that it is better if people often engage in a careful consideration of alternatives.

I feel that it is better if people usually engage in a careful consideration of alternatives.

I feel that it is better if people always engage in a careful consideration of alternatives.

Money (check one).

I strongly believe that money is not one of the most important goals in life.

I believe that money is not one of the most important goals in life.

I feel that perhaps money is not one of the most important goals in life.

I feel that perhaps money is one of the most important goals in life.

I believe that money is one of the most important goals in life.

I strongly believe that money is one of the most important goals in life.

Discipline of Children (check one)

I strongly believe that the father should discipline the children in the family.

I believe that the father should discipline the children in the family.

I feel that perhaps the father should discipline the children in the family.

I feel that perhaps the mother should discipline the children in the family.

I believe that the mother should discipline the children in the family.

I strongly believe that the mother should discipline the children in the family.

Family Finances (check one)

I strongly believe that the man in the family should handle the finances.

I believe that the man in the family should handle the finances.

I feel that perhaps the man in the family should handle the finances.

I feel that perhaps the woman in the family should handle the finances. 
Family Finances (continued)

I believe that the woman in the family should handle the finances.

I strongly believe that the woman in the family should handle the finances.

Careers for Women (check one)

I am very much in favor of women pursuing careers.

I am in favor of women pursuing careers.

I am mildly in favor of women pursuing careers.

I am mildly opposed to women pursuing careers.

I am opposed to women pursuing careers.

I am very much opposed to women pursuing careers.

Welfare Legislation (check one)

I am very much opposed to increased welfare legislation.

I am opposed to increased welfare legislation.

I am mildly opposed to increased welfare legislation.

I am mildly in favor of increased welfare legislation.

I am in favor of increased welfare legislation.

I am very much in favor of increased welfare legis-

lation.

Fresh Air and Exercise (check one)

I strongly believe that fresh air and äaly exercise are not important.

I believe that fresh air and daily exercise are not important.

I feel that probably fresh air and daily exercise are not importnat.

I feel that probably fresh air and daily exercise are important.

I believe that fresh air and daily exercise are important.

I strongly believe that fresh air and daily exercise are important.

A Catholic President (check one)

I am very much in favor of a Catholic being elected president.

I am in favor of a Catholic being elected president.

I am mildly in favor of a Catholic being elected president.

I am mildly against a Catholic being elected president.

I am against a Catholic being elected president.

I am very much against a Catholic being elected president. 
Creative work (check one)

I enjoy doing creative work very much.

I enjoy doing creative work.

I enjoy doing creative work to a slight degree.

I dislike doing creative work to a slight degree.

I dislike doing creative work.

I dislike doing creative work very much.

Sports (check one)

I enjoy sports very much.

I enjoy sports.

I enjoy sports to a slight degree.

I dislike sports to a slight degree.

I dislike sports.

I dislike sports very much.

Fraternities and Sororities (check one)

I am very much against fraternities and sororities as they usually function.

I am against fraternities and sororities as they usually

function.

To a slight degree, I am against fraternities and sororities as they usually function.

To a slight degree, I am in favor of fraternities and sororities as they usually function.

I am in favor of fraternities and sororities as they usually function.

I am very much in favor of fraternities and sororities as they usually function.

Freshmen Having Cars on Campus (check one)

I am very much in favor of freshmen being allowed to have cars on campus.

I am in favor of freshmen being allowed to have cars on campus.

I am in favor of freshmen being allowed to have cars on campus to a slight degree.

I am against freshmen being allowed to have cars on campus to a slight degree.

I am against freshmen being allowed to have cars on campus.

I am very much against freshmen being allowed to have

cars on campus.

Smoking (check one)

In general, I am very much in favor of smoking.

In general, I am in favor of smoking.

In general, I am mildly in favor of smoking. 
Smoking (continued)

In general, I am mildly against smoking.

In general, I am against smoking.

In general, I am very much against smoking.

Dancing (check one)

_ I enjoy dancing very much.

I enjoy dancing.

I enjoy dancing to a slight degree.

I dislike dancing to a slight degree.

I dislike dancing.

I dislike dancing very much.

Novels (check one)

I dislike reading novels very much.

I dislike reading novels.

I dislike reading novels to a slight degree.

I enjoy reading novels to a slight degree.

I enjoy reading novels.

I enjoy reading novels very much.

Classical Music (check one)

I dislike classical music very much.

I dislike classical music.

I dislike classical music to a slight degree.

I enjoy classical music to a slight degree.

I enjoy classical music.

I enjoy classical music very much.

Exhibitions of Modern Art (check one)

I dislike looking at exhibitions of modern art very much.

I dislike looking at exhibitions of modern art.

I dislike looking at exhibitions of modern art to a

slight degree.

I enjoy looking at exhibitions of modern art to a

slight degree.

I enjoy looking at exhibitions of modern art.

I enjoy looking at exhibitions of modern art very much.

Pets (check one)

I enjoy keeping pets very much.

I enjoy keeping pets.

I enjoy keeping pets to a slight degree.

I dislike keeping pets to a slight degree.

I dislike keeping pets.

I dislike keeping pets very much. 
Musical Comedies (check one)

I dislike musical comedies very much.

I dislike musical comedies.

I dislike musical comedies to a slight degree.

I enjoy musical comedies to a slight degree.

I enjoy musical comedies.

I enjoy musical comedies very much.

Tipping (check one)

I am very much opposed to the custom of tipping.

I am opposed to the custon of tipping.

I am mildly opposed to the custom of tipping.

I am mildly in favor of the custom of tipping.

I am in favor of the custom of tipping.

I am very much in favor of the custom of tipping.

Situation Comedies (check one)

I dislike situation comedies very much.

I dislike situation comedies.

I dislike situation comedies to a slight degree.

I enjoy situation comedies to a slight degree.

I enjoy situation comedies.

I enjoy situation comedies very much.

Foreign Movies (check one)

I enjoy foreign movies very much.

I enjoy foreign movies.

I enjoy foreign movies to a slight degree.

I dislike foreign movies to a slight degree.

I dislike foreign movies.

I dislike foreign movies very much.

Western Movies and Television Programs (check one)

I enjoy western movies and television programs very much.

I enjoy western moves and television programs.

I enjoy western movies and television programs to a

slight degree.

I dislike western movies and television programs to

a slight degree.

I dislike western movies and television programs.

I dislike western movies and television programs very

much.

Comedians who Use Satire (check one)

I very much enjoy comedians who use satire.

I enjoy comedians who use satire. 
Comedians Who Use Satire (continued)

I mildly enjoy comedians who use satire.

I mildly dislike comedians who use satire.

I dislike.comedians who use satire.

I very much dislike comedians who use satire.

Gardening (check one)

I enjoy gardening very much.

I enjoy gardening.

I enjoy gardening to a slight degree.

I dislike gardening to a slight degree.

I dislike gardening.

I dislike gardening very much.

Science Fiction (check one)

I enjoy science fiction very much.

I enjoy science fiction.

I enjoy science fiction to a slight degree.

I dislike science fiction to a.slight degree.

I dislike science fiction.

I dislike science fiction very much. 
APPENDIX III

RELATIVE IMPORTANCE OF ATTITUDE TOPICS 
Relative Importance of Attitude Topics

lean Importance

Rating

Topics

Item

No.

\section{Most Important}

3.82

3.62

3.53

3.46

3.38

3.35

3.33

3.31

3.29

3.26

3.16

3.14

3.11

3.06

3.01

2.97

2.95

2.87

2.86

2.85

2.79

2.77

2.75

2.73

2.72

2.71

2.68

2.67

2.64

2.60

2.58

Belief in God

War

College Education

43

American Way of Life

17

Premarital Sex Relations

19

Preparedness for War $\quad 27$

Integration in Publis Schools 10

Nuclear Arms Race 46

One True Religion $\quad 25$

Red China and the U.N. 31

Socialized Medicine 33

Divorce 48

Birth Control 14

Professors and Student Needs 6

14 Next to Most Important

Acting on Impulse 12

Money 21

Discipline of Children 45

Family Finances 53

Careers for Women . 55

Welfare Legislation 28

Grades $\quad 22$

Strict Discipline 39

Draft 51

Financial Help from Parents 40

Undergraduate Marriages 3

State Income Tax 35

Adjustment to Stress 56

Group Opinion $\quad 24$

14 Next to Least Important

Women in Today's Society

Community Bomb Shelters

Necking and Petting 
Relative Importance of Attitude Topics (concluded)

Mean Importance Rating

Topics

Item

No.

2. 57

2.55

2.50

2.45

2.40

2.25

2.15

2.13

1.99

1.98

1.93

1.92

1.84

1.78

1.51

1. 50

1.47

1.35

1.30

1.29

1.27

1.26

1.25

1.25

1.24
Foreign Language

Social Aspects of College

Political parties

Drinking

Dating

Fresh Air and Exercise

A Catholic President

Creative Work

sports

Fraternities and Sororities

Freshmen Cars on Campus

14 Least Important
Smoking

Dancing

Novels

Classical Music

Modern Art

Pets

Musican Comedies

Tipping

Situation Comedies

Foreign Movies

Western Movies on TV

Comedians Who Use Satire

Gardening

science Fiction
42

$\because 13$

23

16

30

44

7

29

18

1

41

9

50

32

15

54

37

26

36

4

38

2 .

11

49

20 
APPENDIX IV

NUMBER OF ITEMS USED BY SUBJECTS IN SEEKING INFORMATION UNDER DIFFERENT INFORMATION CONDITIONS 
NUMBER OF ITEMS USED BY SUBJECTS IN SEEKING INFORMATION UNDER DIFFERENT INFORMATION CONDITIONS

$\begin{array}{cc}\text { SUBJECT } & \text { NUMBER OF ITEMS USED BY SUBJECTS IN SEEKING } \\ \text { INFORMATION UNDER DIFFERENT INFORMATION } \\ \text { CONDITIONS }\end{array}$

\begin{tabular}{|c|c|c|c|c|c|}
\hline & $\operatorname{HISI}^{\star *}$ & LISI & HIDI & LIDI & SUM \\
\hline 1 & 13 & 13 & 7 & 7 & 40 \\
\hline 2 & 7 & 5 & 7 & 3 & 22 \\
\hline 3 & 20 & 10 & 12 & 6 & 48 \\
\hline 4 & 17 & 8 & 3 & 2 & 30 \\
\hline 5 & 15 & 10 & 9 & 8 & 42 \\
\hline 6 & 17 & 12 & 7 & 3 & 39 \\
\hline 7 & 18 & 10 & 8 & 7 & 43 \\
\hline 8 & 10 & 15 & 5 & 6 & 36 \\
\hline 9 & 13 & 7 & 10 & 4 & 34 \\
\hline 10 & 14 & 9 & 20 & 15 & 58 \\
\hline 11 & 11 & 14 & 5 & 3 & 33 \\
\hline 12 & 15 & 12 & 8 & 5 & 40 \\
\hline 13 & 15 & 12 & $7(\mathrm{~A})$ & 3 & 37 \\
\hline 14 & 3 & 3 & 2 & 1 & 9 \\
\hline 15 & 16 & 10 & 4 & 6 & 36 \\
\hline 16 & 15 & 14 & 9 & 11 & 49 \\
\hline 17 & 10 & 7 & 4 & 2 & 23 \\
\hline
\end{tabular}


NUMBER OF ITEMS USED BY SUBJECTS IN SEEKING INFORMATION UNDER DIFFERENT INFORMATION CONDITIONS

\begin{tabular}{lccccc}
\hline & & & & & \\
& & & & \\
18 & 18 & HISI & HIDI & LIDI & SUM \\
\hline 19 & 6 & 17 & 8 & 6 & 49 \\
20 & 18 & 3 & 13 & 7 & 29 \\
\hline Total & 271 & 12 & 8 & 3 & 41 \\
\hline Mean & 13.55 & 10.15 & 7.80 & 5.40 & 36.9 \\
\hline $\begin{array}{l}\text { Standard } \\
\text { Deviation }\end{array}$ & 4.49 & 3.82 & 4.01 & 3.35 & 10.98 \\
\hline
\end{tabular}


SUBJECT* NUMBER OF ITEMS USED BY SUBJECTS IN SEEKING

INFORMATION UNDER DIFFERENT INFORMATION CONDITIONS

\begin{tabular}{|c|c|c|c|c|c|}
\hline 21 & 8 & 9 & 15 & $20(A)$ & 52 \\
\hline 22 & 8 & 10 & 13 & $18(\mathrm{~A})$ & 49 \\
\hline 23 & 4 & 6 & 10 & $20(A)$ & 40 \\
\hline 24 & 4 & 8 & 10 & 16 & 38 \\
\hline 25 & 5 & 9 & 11 & 14 & 39 \\
\hline 26 & 5 & 9 & 12 & 12 & 38 \\
\hline 27 & 2 & 9 & 5 & 6 & 22 \\
\hline 28 & 8 & 11 & 14 & $20(A)$ & 53 \\
\hline 29 & 7 & 10 & 14 & $17(\mathrm{~A})$ & 48 \\
\hline 30 & 8 & 8 & 9 & 15 & 40 \\
\hline 31 & 4 & 6 & 9 & 13 & 32 \\
\hline 32 & 3 & 6 & 9 & 16 & 34 \\
\hline 33 & 5 & 7 & 7 & 12 & 31 \\
\hline 34 & 8 & 11 & 17 & $19(\mathrm{~A})$ & 55 \\
\hline 35 & 8 & 9 & 10 & $19(\mathrm{~A})$ & 46 \\
\hline 36 & 4 & 9 & 9 & $17(\mathrm{~A})$ & 39 \\
\hline 37 & 7 & 8 & 10 & $19(\mathrm{~A})$ & 44 \\
\hline
\end{tabular}


NUMBER OF ITEMS USED BY SUBJECTS IN SEEKING

SUBJECT *

INFORMATION UNDER DIFFERENT INFORMATION

CONDITIONS

38

4

6

15

32

39

6

10

11

$17(A)$

44

40

Total

5

$7 \quad 8$

14

34

Mean

113

168

210

319

810

Mean

5.65

8.40

10.5

15.95

40.50

Standard

Deviation 1.95

1.04

2.97

3.50

8.46 
APPENDIX IV (concluded)

*Subjects 1-20 sought information under close social conditions (roommate). Subjects 2l-40 sought information under distant social conditions (member of general community).

**HISI - High Importance Similar Information LISI - Low Importance Similar Information HIDI - High Importance Dissimilar Information LIDI - Low Importance Dissimilar Information

Note: All subjects accepted individuals on the basis of similarity and rejected individuals on the basis of dissimilarity except where indicated by $(A)$. These subjects accepted dissimilar individuals. 
APPENDIX V

TABLE OF MEANS 
TABLE OF MEANS

Means For the Importance-Similarity Interaction:

\section{High Importance}

9.60

9.15
Low Importance

9.28

10.68

8

Similar Items

Dissimilar Items

\section{(9.15}


APPENDIX VI

PERSONALITY CHARACTERISTICS TEST SCORES 
PERSONALITY CHARACTERISTICS TEST SCORES

\begin{tabular}{|c|c|c|c|}
\hline SUBJECT & RIGIDITY SCALE & $\begin{array}{l}\text { LOCUS OF } \\
\text { CONTROL } \\
\text { SCALE }\end{array}$ & $\begin{array}{l}\text { ACCEPTANCE OF SELE } \\
\text { SCALE }\end{array}$ \\
\hline 1 & -12 & 43 & 42 \\
\hline 2 & 10 & 42 & 75 \\
\hline 3 & 17 & 33 & 58 \\
\hline 4 & 15 & 45 & 69 \\
\hline 5 & 14 & 37 & 70 \\
\hline 6 & 8 & 31 & 61. \\
\hline 7 & 18 & 52 & 88 \\
\hline 8 & 15 & 47 & 66 \\
\hline 9 & 16 & 42 & 63 \\
\hline 10 & 12 & 48 & 69 \\
\hline 1.1 & 19 & 37 & 93 \\
\hline 12 & 19 & 35 & 78 \\
\hline 13 & 14 & 41 & 53 \\
\hline 14 & 15 & 58 & 86 \\
\hline 15 & 21 & 37 & 81 \\
\hline 16 & 18 & 35 & 68 \\
\hline 17 & 14 & 22 & 71 \\
\hline 18 & 13 & 44 & 59 \\
\hline 19 & 12 & 55 & 61 \\
\hline 20 & 16 & 33 & 78 \\
\hline 21 & 19 & 41 & 93 \\
\hline
\end{tabular}


APPENDIX VI (continued)

\begin{tabular}{|c|c|c|c|c|c|}
\hline SUBJECT & RIGIDITY SCALE & $\begin{array}{l}\text { LOCUS OF } \\
\text { CONTROL } \\
\text { SCALE }\end{array}$ & $\begin{array}{c}\text { ACCEPTANCE } \\
\text { SCALE }\end{array}$ & $\mathrm{OF}$ & SELF \\
\hline 22 & 14 & 58 & 53 & & \\
\hline 23 & 18 & 48 & 68 & & \\
\hline 24 & 12 & 35 & 71 & & \\
\hline 25 & 21 & 22 & 88 & & \\
\hline 26 & 15 & 33 & 61 & & \\
\hline 27 & 16 & 44 & 59 & & \\
\hline 28 & 18 & 37 & 61 & & \\
\hline 29 & 12 & 47 & 78 & & \\
\hline 30 & 8 & 33 & 69 & & \\
\hline 31 & 15 & 55 & 81 & & \\
\hline 32 & 14 & 43 & 42 & & \\
\hline 33 & 19 & 31 & 58 & & \\
\hline 34 & 16 & 52 & 70 & & \\
\hline 35 & 16 & 42 & 75 & & \\
\hline 36 & 12 & 47 & 66 & & \\
\hline 37 & 15 & 37 & 68 & & \\
\hline 38 & 19 & 45 & 71 & & \\
\hline 39 & 14 & 48 & 53 & & \\
\hline 40 & 18 & 41 & 63 & & \\
\hline
\end{tabular}


APPENDIX VII

TABLE OF RANDOM PRESENTATION OF SIMILARITY AND ITEM IMPORTANCE VARIABLES COMPIIED FROM STATISTICAI ANALYSIS, A. EDWARDS, RINEHART, N. Y. 
TABLE OF RANDOM PRESENTATION OF SIMILARITY AND ITEM IMPORTANCE VARIABLES COMPILED FROM STATISTICAL ANALYSIS, A. EDWARDS, RINEHART, N. Y.
(1) 2 $2134^{*}$
(21) $1332 \quad 4$
(4I) 21143
(2) $1443 \quad 2$
(22) 12234
(42) $4 \begin{array}{llll}4 & 3 & 2 & 1\end{array}$
(3) $4 \begin{array}{llll}4 & 3 & 2 & 1\end{array}$
(23) 31224
(43) 23314
(4) 13342
(24) 2134
(44) 4312
(5) 3412
(25) 32214
(45) 3421
(26) 4321
(46) 42331
(27) 2341
(47) 3142
(28) 1423
(48) 24431
(29) 24331
(49) 32214
(9) 3142
(30) 2134
(50) 3241
10) 2334
(31) 1243
11) 1423
(32) 4132
12) 3214
(33) 2341
13) 3214
(34) 2134
14) 3412
(35) 4213
15) 1234
(36) 2314
16) 4132
(37) 1324
17) 3124
(38) 2314
18) 14432
(39) $4 \quad 213$
19) 2413
(40) 2143
20) 4132 
APPENDIX VIII

RIGIDITY SCALE 
(TO BE ANSWERED TRUE OR FALSE)

1. I usually don't like to talk much unless I am with people I know very well.

2. I like to talk before groups of people.

3. It is hard for me to start a conversation with strangers.

4. I would like to be an actor on the stage or in the movies.

5. It is hard for me to act natural when I am with new people.

6. I feel nervous if I have to meet a lot of people.

7. I usually feel nervous and ill at ease at a formal dance or party.

8. When I work on a committee I like to take charge of things.

9. I usually take an active part in the entertainment at parties.

10. I am a better talker than listener.

11. I try to remember good stories to pass them on to other people.

12. I am embarrassed with people I do not know well.

13. A strong person doesn't show his emotions and feelings.

14. I must admit that it makes me angry when other people interfere with my daily activity.

15. I find that a well-ordered mode of life with regular hours is congenial to my temperment.

16. It bothers me when something unexpected interrupts my daily routine.

17. I don't like to undertake any project unless I have a pretty good idea as to how it will turn out.

18. I find it hard to set aside a task that I have undertaken, even for a short time.

19. I don't like things to be uncertain and unpredictable. 20. I am very slow in making up my mind. 
RIGIDITY SCALE (concluded)

21. At times I feel that I can make up my mind with unusually great ease.

22. I must admit I try to see what others think before I take a stand.

23. I do not like to see women smoke.

24. I would be uncomfortable in anything other than fairly conventional dress.

25. I keep out of trouble at all costs.

26. It wouldn't make me nervous if any members of my family got into trouble with the law.

27. I must admit that I would find it hard to have for a close friend a person whose manners or appearance made him somewhat repulsive, no matter how brilliant or kind he might be.

28. I would certainly enjoy beating a crook at his own game.

29. I would like a job of a foreign correspondent for a newspaper.

30. I get very tense and anxious when I think other people are diaapproving of me.

31. I am certainly lacking in self-confidence.

32. Criticism or scolding makes me very uncomfortable.

33. Most people inwardly dislike putting themselves out to help other people.

34. I am against giving money to beggars.

35. Many of the girls I knew in college went with a fellow only for what they could get out of him.

36. I always follow the rule: business before pleasure.

37. I get disgusted with myself when I can't understand some problem in my field, or when I can't seem to make any progress on a research problem.

38. I have never been made especially nervous over trouble that any members of my family have gotten into.

39. I have no fear of spiders. 
APPENDIX IX

LOCUS OF CONTROL SCALE 


\title{
LOCUS OF CONTROL SCALE
}

Below are a number of statements about various topics. They have been collected from different groups of people and represent a variety of opinions. There are no right or wrong answers to this questionnair; for every statement there are large numbers of people who agree and disagree. Please indicate whether you agree or disagree with each statement as follows:

\author{
Strongly agree \\ Agree \\ Disagree \\ Strongly disagree
}

Please read each item carefully and be sure that you indicate the response which most closely corresponds to the way which you personally feel.

1. I like to read newspaper editorials whether I agree with them or not.

2. Wars between countries seem inevitable despite effors to prevent them.

3. I believe the government should encourage more young people to make science a career.

4. It is usually true of successful people that their good breaks far outweighted their bad breaks.

5. I believe that moderation in all things is the key to happiness.

6. Many times I feel that we might just as well make many of our decisions by flipping a coin.

7. I disapprove of girls who smoke cigarettes in public places.

8. The actions of other people toward me many times have me baffled.

9. I believe it is more important for a person to like his work than to make money at it.

10. Getting a good job seems to be largely a matter of being lucky enough to be in the right place at the right time.

11. It's not what you know but who you know that really counts in getting ahead. 
LOCUS OF CONTROL SCALE (con't.)

12. A great deal that happens to me is probably just a matter of chance.

13. I don't believe that the presidents of our country should serve for more than two terms.

14. I feel that I have little influence over the way people behave.

15. It is difficult for me to keep well-informed about foreign affairs.

16. Much of the time the future seems uncertain to me.

17. I think the world is much more unsettled now that it was in our grandfather's times.

18. Some people seem born to fail while others seem born for success no matter what they do.

19. I believe there should be less emphasis on spectator sports and more on atrletic participation.

20. It is difficult for ordinalry people to have much control over what politicians do in office.

21. I enjoy reading a good book more than watching television.

22. I feel that many people could be described as victims of circumstances beyond their control.

23. Hollywood movies do not seem as good as they used to be.

24. It seems many times that the grades one gets in school are more dependent on the teachers' whims than on what the student can really do.

25. Money shouldn't be a person's main consideration in choosing a job.

26. It isn't wise to plan too far ahead because most things turn out to be a matter of good or bad fortune anyhow.

27. At one time I wanted to become a newspaper reporter.

28. I can't understand how it is possible to predict other people's behavior.

29. I believe that the U. S. needs a more conservative foreign policy. 
LOCUS OF CONTROL SCALE (cOn't,)

30. When things are going well for me I consider it due to a run of good luck.

31. I believe the government has been taking over too many of the affairs of private industrial management.

32. There's not much use in trying to predict which question a teacher is going to ask on an examination.

33. I get more ideas from talking about things than reading about them.

34. Most people don't realize the extent to which their lives are controlled by accidental happenings.

35. At one time I wanted to be an actor (or actress).

36. I have usually found that what is going to happen will happen, regardless of my actions.

37. Life in a small town offers more real satisfactions than life in a large city.

38. Most of the disappointing things in my life have contained a large element of changce.

39. I would rather be a successful teacher than a successful businessman.

40. I don't believe that a person can really be a master of his fate.

41. I find mathematics easier to study than literature.

42. Success is mostly a matter of getting good breaks.

43. I think it is more important to be respected by people than to be liked by them.

44. Events in the world seem to be beyond the control of most people.

45. I think that states should be allowed to handle racial problems without federal interference.

46. I feel that most people can't really be held responsible for themselves since no one has much choice about where he was born or raised.

47. I like to figure out problems and puzzles that other people have trouble with.

48. Many times the reactions of people seem haphazard to me. 
LOCUS OF CONTROL SCALE (concluded)

49. I rarely lose when playing card games.

50. There's not much use in worrying about things... what will be, will be.

51. I think that everyone should belong to some kind of church.

52. Success in dealing with people seems to be more a matter of the other person's moods and feelings at the time rather than one's own actions.

53. One should not place too much faith in newspaper reports,

54. I think that life is mostly a gamble.

55. I am very stubborn when my mind is made up about something.

56. Many times I feel that I have little influence over the things that happen to me.

57. I like popular music better than classical music.

58. Sometimes I feel that I don't have enough control over the direction my life is taking.

59. I sometimes stick to difficult things too long even when I know they are hopeless.

60. Life is too full of uncertainties. 
APPENDIX $X$

SELF-ACCEPTANCE SCALE 
Not at

$\frac{\text { all true }}{1}$
Half true

$\frac{\text { half false }}{3}$
Completely

$\frac{\text { true }}{5}$

1. I'd like it if I could find someone who would tell me how to solve my personal problems.

2. I don't question. my worth as a person, even if I think others do.

3. When people say nice things about me, I find it difficult to believe they really mean it. I think maybe they're kidding me or just aren't being sincere.

4. If there is any criticism or anyone says anthing about me, I just can't take it.

5. I don't say much at social affairs because I'm afraid that people will criticize me or laugh if I say the wrong thing.

6. I realize that I'm not living very effectively, but I just don't believe I've got it in me to use my energies in better ways.

7. I look on most of the feelings and impulses I have toward people as being quite natural and acceptable.

8. Something inside me just won't let me be satisfied with any job I've done--if it turns out well, I get a very smug felling that his is beneath me, I shouldn't be satisfied with this, this isn't a fair test.

9. I feel different from other people. I'd like to have the feeling of security that comes from knowing I'm not too different from others.

10. I'm afraid for people that I like to find out what I'm really like, for fear they'd be disappointed in me.

11. I am frequently bothered by feelings of inferiority.

12. Because of other people, I haven't been able to achieve as much as I should have.

13. I am quite shy and self-conscious in social situations. 
SELF-ACCEPTANCE SCALE (con't,)

14. In order to get along and be liked, I tend to be what people expect me to be rather than anything else.

15. I seem to have a real inner strength in handling things. I'm on a pretty solid foundation and it makes me pretty sure of myself.

16. I feel self-conscious when I'm with people who have a superior position to mine in business or at school.

17. I think I'm neurotic or something.

18. Very often, I don't try to be friendly with people because I think they won't like me.

19. I feel that I'm a person of worth, on an equal plane with others.

20. I can't avoid feeling guilty about the way I feel toward certain people in my life.

21. I'm not afraid of meeting new people. I feel that I'm a worth-while person and there's no reason why they should dislike me.

22. I sort of only half-believe in myself.

23. I'm very sensitive. People say things and I have a tendency to think they're criticizing me or insulting me in some way and later when I think of it, they may not have meant anything like that at all.

24. I think I have certain abilities and other people say so too. I wonder if I'm not giving them an importance way beyond what they deserve.

25. I feel confident that I can do something about the prolem that may arise in the future.

26. I guess I put on a show to impress people. I know I'm not the person I pretend to be.

27. I do not worry ro condemn myself if other people pass judgment against me.

28. I don't feel very normal, but I want to feel normal.

29. When I'm in a group I usually don't say much for fear of saying the wrong thing.

30. I have a tendency to sidestep my problems. 
SELF-ACCEPTANCE SCALE. (con't.)

31. Even when people do think well of me, I feel sort of guilty because I know I must be fooling them--that if I were really to be myself, they wouldn't think well of me.

32. I feel that I'm on the same level as other people and that helps to establish good relations with them.

33. I feel that people are apt to react differently to me than they would normally react to other people.

34. I live too much by other people's standards.

35. When I have to address a group, I get self-conscious and have difficulty saying things well.

36. If I didn't always have such hard luck, I'd accomplish much more than I have. 
APPENDIX XI.

ADDITIONAL INFORMATION ON SUBJECTS 
ADDITIONAL INFORMATION ON SUBJECTS

Subjects were selected from the wheaton College undergraduate class. Wheaton is an all girls college located in Norton, Massachusetts and most of its student body are from an upper middle class population, mainly white.

Though random selection was used each class was represented so that there were 10 freshmen, 10 sophmores, 10 juniors and 10 seniors. 